\title{
Recommendations on the Use of Ultrasound Guidance for Central and Peripheral Vascular Access in Adults: A Position Statement of the Society of Hospital Medicine
}

\author{
Ricardo Franco-Sadud, MD*, Daniel Schnobrich, MD², Benji K. Mathews, MD³, Carolina Candotti, MD4, \\ Saaid Abdel-Ghani, MD5, Martin G Perez, MD ${ }^{6}$, Sophia Chu Rodgers, DNP, ACNP7 , Michael J Mader, MS ${ }^{8,9}$, Elizabeth K Haro, \\ $\mathrm{MPH}^{8,9}$, Ria Dancel, MD10,11, Joel Cho, MD, RDMS, RDCS ${ }^{12}$, Loretta Grikis, MLS ${ }^{13}$, Brian P Lucas, MD, MS ${ }^{13,14}$, \\ the SHM Point-of-care Ultrasound Task Force**, and Nilam J Soni, MD, MS ${ }^{8,9}$
}

\begin{abstract}
${ }^{1}$ Naples Community Hospital Health System, University of Central Florida; ${ }^{2}$ Divisions of General Internal Medicine and Hospital Pediatrics, University of Minnesota, Minneapolis, Minnesota; ${ }^{3}$ Department of Hospital Medicine, Regions Hospital, Health Partners, St. Paul, Minnesota; ${ }^{4}$ Division of Hospital Medicine, University of California Davis, Davis, California; ${ }^{5}$ Department of Hospital Medicine, Medical Subspecialties Institute, Cleveland Clinic Abu Dhabi, Abu Dhabi, UAE; ${ }^{6}$ Department of Hospital Medicine, Memorial Hermann Northeast Hospital, Humble, Texas; ${ }^{7}$ Division of Pulmonary Critical Care Medicine, Lovelace Health Systems, Albuquerque, New Mexico; ${ }^{8}$ Division of General \& Hospital Medicine, University of Texas Health San Antonio, San Antonio, Texas; ${ }^{9}$ Section of Hospital Medicine, South Texas Veterans Health Care System, San Antonio, Texas; ${ }^{10}$ Division of Hospital Medicine, University of North Carolina, Chapel Hill, North Carolina; ${ }^{11}$ Division of General Pediatrics and Adolescent Medicine, University of North Carolina, Chapel Hill, North Carolina; ${ }^{12}$ Department of Hospital Medicine, Kaiser Permanente Medical Center, San Francisco, California; ${ }^{13}$ Medicine Service, White River Junction VA Medical Center, White River Junction, Vermont; ${ }^{14}$ Geisel School of Medicine at Dartmouth College, Hanover, New Hampshire.
\end{abstract}

\section{PREPROCEDURE}

1) We recommend that providers should be familiar with the operation of their specific ultrasound machine prior to initiation of a vascular access procedure.

2) We recommend that providers should use a highfrequency linear transducer with a sterile sheath and sterile gel to perform vascular access procedures.

3) We recommend that providers should use twodimensional ultrasound to evaluate for anatomical variations and absence of vascular thrombosis during preprocedural site selection.

4) We recommend that providers should evaluate the target blood vessel size and depth during preprocedural ultrasound evaluation.

\section{TECHNIQUES}

\section{General Techniques}

5) We recommend that providers should avoid using static ultrasound alone to mark the needle insertion site for vascular access procedures.

6) We recommend that providers should use real-time (dynamic), two-dimensional ultrasound guidance with a high-frequency linear transducer for central venous catheter (CVC) insertion, regardless of the provider's level of experience.

7) We suggest using either a transverse (short-axis) or longitudinal (long-axis) approach when performing realtime ultrasound-guided vascular access procedures.

8) We recommend that providers should visualize the needle tip and guidewire in the target vein prior to vessel dilatation.

9) To increase the success rate of ultrasound-guided vascular access procedures, we recommend that providers should utilize echogenic needles, plastic needle guides, and/or ultrasound beam steering when available.

\section{Central Venous Access Techniques}

10) We recommend that providers should use a standardized procedure checklist that includes the use of real-time ultrasound guidance to reduce the risk of central line-associated bloodstream infection (CLABSI) from CVC insertion.

11) We recommend that providers should use real-time ultrasound guidance, combined with aseptic technique and maximal sterile barrier precautions, to reduce the incidence of infectious complications from CVC insertion.

12) We recommend that providers should use realtime ultrasound guidance for internal jugular vein catheterization, which reduces the risk of mechanical and infectious complications, the number of needle passes, and time to cannulation and increases overall procedure success rates.

13) We recommend that providers who routinely insert subclavian vein CVCs should use real-time ultrasound guidance, which has been shown to reduce the risk of mechanical complications and number of needle passes and increase overall procedure success rates compared with landmark-based techniques.

14) We recommend that providers should use real-time ultrasound guidance for femoral venous access, which has been shown to reduce the risk of arterial punctures and total procedure time and increase overall procedure success rates.

\section{Peripheral Venous Access Techniques}

15) We recommend that providers should use real-time ultrasound guidance for the insertion of peripherally inserted central catheters (PICCs), which is associated with 
higher procedure success rates and may be more cost effective compared with landmark-based techniques.

16) We recommend that providers should use real-time ultrasound guidance for the placement of peripheral intravenous lines (PIV) in patients with difficult peripheral venous access to reduce the total procedure time, needle insertion attempts, and needle redirections. Ultrasoundguided PIV insertion is also an effective alternative to CVC insertion in patients with difficult venous access.

17) We suggest using real-time ultrasound guidance to reduce the risk of vascular, infectious, and neurological complications during PIV insertion, particularly in patients with difficult venous access.

\section{Arterial Access Techniques}

18) We recommend that providers should use real-time ultrasound guidance for arterial access, which has been shown to increase first-pass success rates, reduce the time to cannulation, and reduce the risk of hematoma development compared with landmark-based techniques.

19) We recommend that providers should use real-time ultrasound guidance for femoral arterial access, which has been shown to increase first-pass success rates and reduce the risk of vascular complications.

20) We recommend that providers should use real-time ultrasound guidance for radial arterial access, which has been shown to increase first-pass success rates, reduce the time to successful cannulation, and reduce the risk of complications compared with landmark-based techniques.

\section{POSTPROCEDURE}

21) We recommend that post-procedure pneumothorax should be ruled out by the detection of bilateral lung sliding using a high-frequency linear transducer before and after insertion of internal jugular and subclavian vein CVCs.

22) We recommend that providers should use ultrasound with rapid infusion of agitated saline to visualize a right atrial swirl sign (RASS) for detecting catheter tip misplacement during CVC insertion. The use of RASS to detect the catheter tip may be considered an advanced skill that requires specific training and expertise.

\section{TRAINING}

23) To reduce the risk of mechanical and infectious complications, we recommend that novice providers should complete a systematic training program that includes a combination of simulation-based practice, supervised insertion on patients, and evaluation by an expert operator before attempting ultrasound-guided CVC insertion independently on patients.

24) We recommend that cognitive training in ultrasoundguided CVC insertion should include basic anatomy, ultrasound physics, ultrasound machine knobology, fundamentals of image acquisition and interpretation, detection and management of procedural complications, infection prevention strategies, and pathways to attain competency.

25) We recommend that trainees should demonstrate minimal competence before placing ultrasound-guided CVCs independently. A minimum number of CVC insertions may inform this determination, but a proctored assessment of competence is most important.

26) We recommend that didactic and hands-on training for trainees should coincide with anticipated times of increased performance of vascular access procedures. Refresher training sessions should be offered periodically.

27) We recommend that competency assessments should include formal evaluation of knowledge and technical skills using standardized assessment tools.

28) We recommend that competency assessments should evaluate for proficiency in the following knowledge and skills of CVC insertion: (a) Knowledge of the target vein anatomy, proper vessel identification, and recognition of anatomical variants; (b) Demonstration of CVC insertion with no technical errors based on a procedural checklist; (c) Recognition and management of acute complications, including emergency management of life-threatening complications; (d) Real-time needle tip tracking with ultrasound and cannulation on the first attempt in at least five consecutive simulation.

29) We recommend a periodic proficiency assessment of all operators should be conducted to ensure maintenance of competency.

Journal of Hospital Medicine. 2019;14:E1-E22 (C) 2019 Society of Hospital Medicine
*Corresponding Author: Ricardo A. Franco-Sadud, MD; E-mail: Ricardo .FrancoSadud@nchmd.org; Telephone: 239-624-0940.

Find Additional Supporting Information in the online version of this article.

Received: February 4, 2019; Revised: July 8, 2019; Accepted: July 9, 2019

(c) 2019 Society of Hospital Medicine DOI 10.12788/jhm.3287

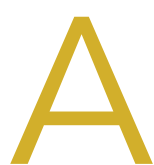

pproximately five million central venous catheters (CVCs) are inserted in the United States annually, with over 15 million catheter days documented in intensive care units alone. ' Traditional CVC insertion techniques using landmarks are associated with a high risk of mechanical complications, particularly pneumothorax and arterial puncture, which occur in 5\%-19\% patients. ${ }^{2,3}$

Since the 1990s, several randomized controlled studies and meta-analyses have demonstrated that the use of real-time ultrasound guidance for CVC insertion increases procedure 
success rates and decreases mechanical complications. ${ }^{4,5}$ Use of real-time ultrasound guidance was recommended by the Agency for Healthcare Research and Quality, the Institute of Medicine, the National Institute for Health and Care Excellence, the Centers for Disease Control and Prevention, and several medical specialty societies in the early 2000s. ${ }^{6-14} \mathrm{De}$ spite these recommendations, ultrasound guidance has not been universally adopted. Currently, an estimated 20\%-55\% of CVC insertions in the internal jugular vein are performed without ultrasound guidance. ${ }^{15-17}$

Following the emergence of literature supporting the use of ultrasound guidance for CVC insertion, observational and randomized controlled studies demonstrated improved procedural success rates with the use of ultrasound guidance for the insertion of peripheral intravenous lines (PIVs), arterial catheters, and peripherally inserted central catheters (PICCs). ${ }^{18-23}$

The purpose of this position statement is to present evidence-based recommendations on the use of ultrasound guidance for the insertion of central and peripheral vascular access catheters in adult patients. This document presents consensus-based recommendations with supporting evidence for clinical outcomes, techniques, and training for the use of ultrasound guidance for vascular access. We have subdivided the recommendations on techniques for central venous access, peripheral venous access, and arterial access individually, as some providers may not perform all types of vascular access procedures.

These recommendations are intended for hospitalists and other healthcare providers that routinely place central and peripheral vascular access catheters in acutely ill patients. However, this position statement does not mandate that all hospitalists should place central or peripheral vascular access catheters given the diverse array of hospitalist practice settings. For training and competency assessments, we recognize that some of these recommendations may not be feasible in resource-limited settings, such as rural hospitals, where equipment and staffing for assessments are not available. Recommendations and frameworks for initial and ongoing credentialing of hospitalists in ultrasound-guided bedside procedures have been previously published in an Society of Hospital Medicine (SHM) position statement titled, "Credentialing of Hospitalists in Ultrasound-Guided Bedside Procedures." 24

\section{METHODS}

Detailed methods are described in Appendix 1. The SHM Point-of-care Ultrasound (POCUS) Task Force was assembled to carry out this guideline development project under the direction of the SHM Board of Directors, Director of Education, and Education Committee. All expert panel members were physicians or advanced practice providers with expertise in POCUS. Expert panel members were divided into working group members, external peer reviewers, and a methodologist. All Task Force members were required to disclose any potential conflicts of interest (Appendix 2). The literature search was conducted in two independent phases. The first phase included literature searches conducted by the vascular access working group members themselves. Key clinical questions and draft recommendations were then prepared. A systematic literature search was conducted by a medical librarian based on the findings of the initial literature search and draft recommendations. The Medline, Embase, CINAHL, and Cochrane medical databases were searched from 1975 to December 2015 initially. Google Scholar was also searched without limiters. An updated search was conducted in November 2017. The literature search strings are included in Appendix 3. All article abstracts were initially screened for relevance by at least two members of the vascular access working group. Full-text versions of screened articles were reviewed, and articles on the use of ultrasound to guide vascular access were selected. The following article types were excluded: non-English language, nonhuman, age $<18$ years, meeting abstracts, meeting posters, narrative reviews, case reports, letters, and editorials. All relevant systematic reviews, meta-analyses, randomized controlled studies, and observational studies of ultrasound-guided vascular access were screened and selected (Appendix 3, Figure 1). All full-text articles were shared electronically among the working group members, and final article selection was based on working group consensus. Selected articles were incorporated into the draft recommendations.

These recommendations were developed using the Research and Development (RAND) Appropriateness Method that required panel judgment and consensus. ${ }^{14}$ The 28 voting members of the SHM POCUS Task Force reviewed and voted on the draft recommendations considering five transforming factors: (1) Problem priority and importance, (2) Level of quality of evidence, (3) Benefit/harm balance, (4) Benefit/burden balance, and (5) Certainty/concerns about PEAF (Preferences/Equity/Acceptability/Feasibility). Using an internet-based electronic data collection tool (REDCap ${ }^{\mathrm{TM}}$ ), panel members participated in two rounds of electronic voting, one in August 2018 and the other in October 2018 (Appendix 4). Voting on appropriateness was conducted using a nine-point Likert scale. The three zones of the nine-point Likert scale were inappropriate (1-3 points), uncertain (4-6 points), and appropriate (7-9 points). The degree of consensus was assessed using the RAND algorithm (Appendix 1, Figure 1 and Table 1). Establishing a recommendation required at least $70 \%$ agreement that a recommendation was "appropriate." Disagreement was defined as $>30 \%$ of panelists voting outside of the zone of the median. A strong recommendation required at least $80 \%$ of the votes within one integer of the median per the RAND rules.

Recommendations were classified as strong or weak/conditional based on preset rules defining the panel's level of consensus, which determined the wording for each recommendation (Table 2). The final version of the consensus-based recommendations underwent internal and external review by members of the SHM POCUS Task Force, the SHM Education Committee, and the SHM Executive Committee. The SHM Executive Committee reviewed and approved this position statement prior to its publication in the Journal of Hospital Medicine. 
TABLE 1. Definitions of Levels of Consensus

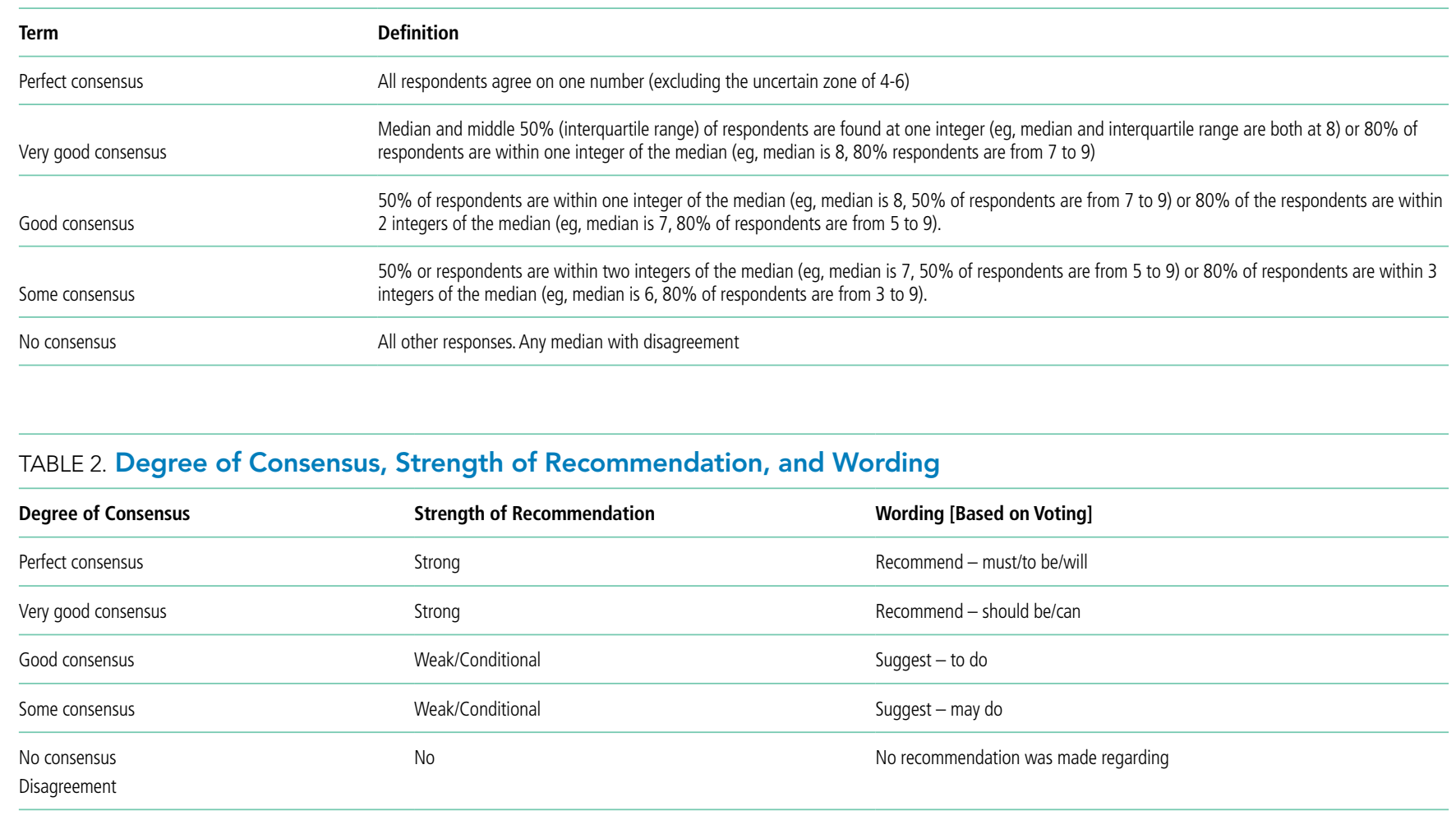

\section{RESULTS}

\section{Literature Search}

A total of 5,563 references were pooled from an initial search performed by a certified medical librarian in December 2015 (4,668 citations) which was updated in November 2017 (791 citations), and from the personal bibliographies and searches (104 citations) performed by working group members. A total of 514 full-text articles were reviewed. The final selection included 192 articles that were abstracted into a data table and incorporated into the draft recommendations. See Appendix 3 for details of the literature search strategy.

\section{Recommendations}

Four domains (technique, clinical outcomes, training, and knowledge gaps) with 31 draft recommendations were generated based on a review of the literature. Selected references were abstracted and assigned to each draft recommendation. Rationales for each recommendation cite supporting evidence. After two rounds of panel voting, 31 recommendations achieved agreement based on the RAND rules. During the peer review process, two of the recommendations were merged with other recommendations. Thus, a total of 29 recommendations received final approval. The degree of consensus based on the median score and the dispersion of voting around the median are shown in Appendix 5. Twenty-seven statements were approved as strong recommendations, and two were approved as weak/conditional recommendations. The strength of each recommendation and degree of consensus are summarized in Table 3.

\section{Terminology}

\section{Central Venous Catheterization}

Central venous catheterization refers to insertion of tunneled or nontunneled large bore vascular catheters that are most commonly inserted into the internal jugular, subclavian, or femoral veins with the catheter tip located in a central vein. These vascular access catheters are synonymously referred to as central lines or central venous catheters (CVCs). Nontunneled catheters are designed for short-term use and should be removed promptly when no longer clinically indicated or after a maximum of 14 days. ${ }^{25}$ In this document, CVCs or central lines refer to nontunneled catheters, unless otherwise stated. (Note: For this guideline document, PICC lines, although technically considered to be central lines, will be specifically referred to as PICC lines and should not be presumed to be included in recommendations about central venous catheters).

\section{Peripherally Inserted Central Catheter (PICC)}

Peripherally inserted central catheters, or PICC lines, are inserted most commonly in the basilic or brachial veins in adult patients, and the catheter tip terminates in the distal superior vena cava or cavo-atrial junction. These catheters are designed to remain in place for a duration of several weeks, as long as it is clinically indicated.

\section{Midline Catheterization}

Midline catheters are a type of peripheral venous catheter that are an intermediary between a peripheral intravenous catheter 


\section{TABLE 3. Summary of Recommendations}

\begin{tabular}{ll}
$\begin{array}{l}\text { No. Topic of Recommendation } \\
\text { Preprocedure }\end{array}$ & $\begin{array}{c}\text { Strength of } \\
\text { Recommendation }\end{array}$ \\
\hline $\begin{array}{l}\text { Be familiar with operation of the specific ultrasound machine. } \\
\text { Use high-frequency linear transducers with a sterile sheath and sterile gel to perform vascular access procedures with full sterile } \\
\text { precautions. }\end{array} \quad$ Use two-dimensional ultrasound to evaluate for anatomical variations and absence of vascular thrombosis. \\
\hline $3 \quad$ Evaluate the target blood vessel size and depth. \\
\hline $4 \quad$ Strong Gory Good
\end{tabular}

Techniques

General Techniques

\begin{tabular}{|c|c|c|c|}
\hline 5 & Avoid using static ultrasound to mark a needle insertion site. & Very Good & Strong \\
\hline 6 & Use real-time (dynamic), 2-dimensional ultrasound guidance with a high-frequency linear transducer. & Very Good & Strong \\
\hline 7 & Use either a transverse (short-axis) or longitudinal (long-axis) approach. & Good & Weak \\
\hline 8 & Visualize the needle tip and guidewire in the target vein before dilatation. & Very Good & Strong \\
\hline 9 & Utilize echogenic needles, plastic needle guides, and/or ultrasound beam steering when available. & Very Good & Strong \\
\hline \multicolumn{4}{|c|}{ Central Venous Access Techniques } \\
\hline 10 & Use a standardized procedure checklist. & Very Good & Strong \\
\hline 11 & Use real-time ultrasound guidance, aseptic technique, and maximal sterile barrier precautions. & Very Good & Strong \\
\hline 12 & $\begin{array}{l}\text { Internal Jugular Vein: Use real-time ultrasound guidance to reduce the risk of mechanical and infectious complications, reduce the number } \\
\text { of needle passes, reduce the time to cannulation, and increase procedure success rates. }\end{array}$ & Very Good & Strong \\
\hline 13 & $\begin{array}{l}\text { Subclavian Vein: Use real-time ultrasound guidance to reduce the risk of mechanical complications and number of needle passes, and } \\
\text { increase procedure success rates. }\end{array}$ & Very Good & Strong \\
\hline 14 & $\begin{array}{l}\text { Femoral Vein: Use real-time ultrasound guidance to reduce the risk of arterial punctures and total procedure time, and increase procedure } \\
\text { success rates. }\end{array}$ & Very Good & Strong \\
\hline \multicolumn{4}{|c|}{ Peripheral Venous Access Techniques } \\
\hline 15 & Use real-time ultrasound guidance for insertion of Peripherally Inserted Central Catheters to improve procedure success rates. & Very Good & Strong \\
\hline 16 & $\begin{array}{l}\text { Use real-time ultrasound guidance for placement of PIV lines in patients with difficult peripheral venous access to reduce procedure time, } \\
\text { needle insertion attempts, and needle redirections. }\end{array}$ & Very Good & Strong \\
\hline 17 & Use real-time ultrasound guidance to reduce the risk of vascular, infectious, and neurological complications during PIV insertion. & Good & Weak \\
\hline
\end{tabular}

\section{Arterial Access Techniques}

18 Use real-time ultrasound guidance for arterial access to increase the first-pass success rates, reduce the time to cannulation, and reduce the risk of hematoma development.

Use real-time ultrasound guidance for arterial access to increase the first-pass success rates, reduce the time to cannulation, and reduce the
risk of hematoma development.
$\begin{aligned} & \text { Use real-time ultrasound guidance for femoral arterial access to increase the first-pass success rates and reduce the risk of vascular } \\ & \text { complications. }\end{aligned}$
Use real-time ultrasound guidance for radial artery access to increase the first-pass success rate, reduce the time to cannulation, and reduce
the risk of complications.

Postprocedure

21 Rule out postprocedure pneumothorax by detection of bilateral lung sliding using a high-frequency linear transducer.
$22 \quad \begin{aligned} & \text { Use ultrasound with rapid infusion of agitated saline to visualize a right atrial swirl sign to detect catheter tip misplacement during CVC } \\ & \text { insertion. }\end{aligned}$


TABLE 3. Summary of Recommendations (continued)

\begin{tabular}{|c|c|c|c|}
\hline No. & Topic of Recommendation & $\begin{array}{c}\text { Strength of } \\
\text { Recommendation }\end{array}$ & $\begin{array}{l}\text { Degree of } \\
\text { Consensus }\end{array}$ \\
\hline \multicolumn{4}{|c|}{ Training } \\
\hline 23 & $\begin{array}{l}\text { Complete a systematic training program with simulation-based practice, supervised insertions, and evaluation by an expert operator } \\
\text { ultrasound-guided CVC insertion. }\end{array}$ & Very Good & Strong \\
\hline 24 & $\begin{array}{l}\text { Cognitive training in ultrasound-guided CVC insertion should include basic anatomy, ultrasound physics, ultrasound machine knobology, } \\
\text { fundamentals of image acquisition and interpretation, detection and management of procedural complications, infection prevention } \\
\text { strategies, and pathways to attain competency. }\end{array}$ & Very Good & Strong \\
\hline 25 & Demonstrate minimal competence before placing ultrasound-guided CVCs independently. & Very Good & Strong \\
\hline 26 & Didactic and hands-on training for trainees should coincide with anticipated times of increased performance of vascular access procedures. & Very Good & Strong \\
\hline 27 & Competency assessments with standardized assessment tools should evaluate knowledge and technical skills. & Very Good & Strong \\
\hline 28 & $\begin{array}{l}\text { Knowledge and skills competency assessments for CVC insertion should include } \\
\text { a) Anatomy of the target vein } \\
\text { b) Demonstration of CVC insertion using a procedural checklist. } \\
\text { c) Recognition and management of acute complications } \\
\text { d) Real-time needle tip tracking with ultrasound and cannulation. }\end{array}$ & Very Good & Strong \\
\hline 29 & Conduct periodic proficiency assessments of all operators to ensure maintenance of competency. & Very Good & Strong \\
\hline
\end{tabular}

and PICC line. Midline catheters are most commonly inserted in the brachial or basilic veins, but unlike PICC lines, the tips of these catheters terminate in the axillary or subclavian vein. Midline catheters are typically $8 \mathrm{~cm}$ to $20 \mathrm{~cm}$ in length and inserted for a duration $<30$ days.

\section{Peripheral Intravenous Catheterization}

Peripheral intravenous lines (PIV) refer to small bore venous catheters that are most commonly $14 G$ to $24 G$ and inserted into patients for short-term peripheral venous access. Common sites of ultrasound-guided PIV insertion include the superficial and deep veins of the hand, forearm, and arm.

\section{Arterial Catheterization}

Arterial catheters are commonly used for reliable blood pressure monitoring, frequent arterial blood sampling, and cardiac output monitoring. The most common arterial access sites are the femoral and radial arteries.

\section{RECOMMENDATIONS}

\section{Preprocedure}

\section{We recommend that providers should be familiar with} the operation of their specific ultrasound machine prior to initiation of a vascular access procedure.

Rationale: There is strong consensus that providers must be familiar with the knobs and functions of the specific make and model of ultrasound machine that will be utilized for a vascular access procedure. Minimizing adjustments to the ultrasound machine during the procedure may reduce the risk of contaminating the sterile field.
2. We recommend that providers should use a high-frequency linear transducer with a sterile sheath and sterile gel to perform vascular access procedures.

Rationale: High-frequency linear-array transducers are recommended for the vast majority of vascular access procedures due to their superior resolution compared to other transducer types. Both central and peripheral vascular access procedures, including PIV, PICC, and arterial line placement, should be performed using sterile technique. A sterile transducer cover and sterile gel must be utilized, and providers must be trained in sterile preparation of the ultrasound transducer. 13,26,27

The depth of femoral vessels correlates with body mass index (BMI). When accessing these vessels in a morbidly obese patient with a thigh circumference $>60 \mathrm{~cm}$ and vessel depth $>8 \mathrm{~cm}$, a curvilinear transducer may be preferred for its deeper penetration. ${ }^{28}$ For patients who are poor candidates for bedside insertion of vascular access catheters, such as uncooperative patients, patients with atypical vascular anatomy or poorly visualized target vessels, we recommend consultation with a vascular access specialist prior to attempting the procedure.

3. We recommend that providers should use two-dimensional ultrasound to evaluate for anatomical variations and absence of vascular thrombosis during preprocedural site selection.

Rationale: A thorough ultrasound examination of the target vessel is warranted prior to catheter placement. Anatomical variations that may affect procedural decision-making are easily detected with ultrasound. A focused vascular ultrasound examination is particularly important in patients who have had 
temporary or tunneled venous catheters, which can cause stenosis or thrombosis of the target vein.

For internal jugular vein (IJV) CVCs, ultrasound is useful for visualizing the relationship between the IJV and common carotid artery (CCA), particularly in terms of vessel overlap. Furthermore, ultrasound allows for immediate revisualization upon changes in head position. ${ }^{29-32}$ Troianos et al. found $>75 \%$ overlap of the IJV and CCA in 54\% of all patients and in $64 \%$ of older patients (age $>60$ years) whose heads were rotated to the contralateral side. ${ }^{30}$ In one study of IJV CVC insertion, inadvertent carotid artery punctures were reduced (3\% vs 10\%) with the use of ultrasound guidance vs landmarks alone. ${ }^{33}$ In a cohort of 64 high-risk neurosurgical patients, cannulation success was $100 \%$ with the use of ultrasound guidance, and there were no injuries to the carotid artery, even though the procedure was performed with a 30-degree head elevation and anomalous IJV anatomy in 39\% of patients. ${ }^{34}$ In a prospective, randomized controlled study of 1,332 patients, ultrasound-guided cannulation in a neutral position was demonstrated to be as safe as the 45-degree rotated position. ${ }^{35}$

Ultrasound allows for the recognition of anatomical variations which may influence the selection of the vascular access site or technique. Benter et al. found that $36 \%$ of patients showed anatomical variations in the IJV and surrounding tissue. ${ }^{36}$ Similarly Caridi showed the anatomy of the right IJV to be atypical in $29 \%$ of patients, ${ }^{37}$ and Brusasco found that $37 \%$ of bariatric patients had anatomical variations of the IJV. ${ }^{38}$ In a study of 58 patients, there was significant variability in the IJV position and IJV diameter, ranging from $0.5 \mathrm{~cm}$ to $>2 \mathrm{~cm} .{ }^{39} \mathrm{In}$ a study of hemodialysis patients, $75 \%$ of patients had sonographic venous abnormalities that led to a change in venous access approach. ${ }^{40}$

To detect acute or chronic upper extremity deep venous thrombosis or stenosis, two-dimensional visualization with compression should be part of the ultrasound examination prior to central venous catheterization. In a study of patients that had undergone CVC insertion 9-19 weeks earlier, 50\% of patients had an IJV thrombosis or stenosis leading to selection of an alternative site. In this study, use of ultrasound for a preprocedural site evaluation reduced unnecessary attempts at catheterizing an occluded vein. ${ }^{41}$ At least two other studies demonstrated an appreciable likelihood of thrombosis. In a study of bariatric patients, $8 \%$ of patients had asymptomatic thrombosis ${ }^{38}$ and in another study, 9\% of patients being evaluated for hemodialysis catheter placement had asymptomatic IJV thrombosis. ${ }^{37}$

\section{We recommend that providers should evaluate the tar- get blood vessel size and depth during a preprocedural ultrasound evaluation.}

Rationale: The size, depth, and anatomic location of central veins can vary considerably. These features are easily discernable using ultrasound. Contrary to traditional teaching, the IJV is located $1 \mathrm{~cm}$ anterolateral to the CCA in only about twothirds of patients. ${ }^{37,39,42,43}$ Furthermore, the diameter of the IJV can vary significantly, ranging from $0.5 \mathrm{~cm}$ to $>2 \mathrm{~cm} .{ }^{39}$ The laterality of blood vessels may vary considerably as well. A preprocedural ultrasound evaluation of contralateral subclavian and axillary veins showed a significant absolute difference in cross-sectional area of $26.7 \mathrm{~mm}^{2}(P<.001) .42$

Blood vessels can also shift considerably when a patient is in the Trendelenburg position. In one study, the IJV diameter changed from $11.2( \pm 1.5) \mathrm{mm}$ to $15.4( \pm 1.5) \mathrm{mm}$ in the supine versus the Trendelenburg position at 15 degrees. ${ }^{33}$ An observational study demonstrated a frog-legged position with reverse Trendelenburg increased the femoral vein size and reduced the common surface area with the common femoral artery compared to a neutral position. Thus, a frog-legged position with reverse Trendelenburg position may be preferred, since overall catheterization success rates are higher in this position. ${ }^{44}$

\section{Techniques}

\section{General Techniques}

\section{We recommend that providers should avoid using static ultrasound alone to mark the needle insertion site for vascular access procedures.}

Rationale: The use of static ultrasound guidance to mark a needle insertion site is not recommended because normal anatomical relationships of vessels vary, and site marking can be inaccurate with minimal changes in patient position, especially of the neck. ${ }^{43,45,46}$ Benefits of using ultrasound guidance for vascular access are attained when ultrasound is used to track the needle tip in real-time as it is advanced toward the target vessel.

Although continuous-wave Doppler ultrasound without two-dimensional visualization was used in the past, it is no longer recommended for IJV CVC insertion. ${ }^{47}$ In a study that randomized patients to IJV CVC insertion with continuous-wave Doppler alone vs two-dimensional ultrasound guidance, the use of two-dimensional ultrasound guidance showed significant improvement in first-pass success rates $(97 \%$ vs $91 \%, P=.045)$, particularly in patients with $\mathrm{BMI}>30(97 \%$ vs $77 \%, P=.011) .{ }^{48}$

$A$ randomized study comparing real-time ultrasound-guided, landmark-based, and ultrasound-marked techniques found higher success rates in the real-time ultrasound-guided group than the other two groups $(100 \%$ vs $74 \%$ vs $73 \%$, respectively; $P=.01$ ). The total number of mechanical complications was higher in the landmark-based and ultrasound-marked groups than in the real-time ultrasound-guided group (24\% and $36 \%$ versus $0 \%$, respectively; $P=.01) .{ }^{49}$ Another randomized controlled study found higher success rates with real-time ultrasound guidance (98\%) versus an ultrasound-marked (82\%) or landmark-based (64\%) approach for central line placement. ${ }^{50}$

\section{We recommend that providers should use real-time (dynamic), two-dimensional ultrasound guidance with a high-frequency linear transducer for CVC insertion, regardless of the provider's level of experience.}


Rationale: Ultrasound-guided CVCs are most commonly inserted using real-time ultrasound guidance with a high-frequency linear transducer. ${ }^{28,43,44,51,52}$ When adequately trained, ultrasound guidance for CVC insertion may be beneficial for all operators, regardless of prior experience. The use of ultrasound guidance for CVC insertion has been shown to provide greater benefit in operators with less experience compared to those with greater experience..$^{53}$ A prospective, observational study of patients undergoing elective ultrasound-guided CVC insertion found an overall procedure complication rate of $19.5 \%$. There were significantly more complications in procedures performed by operators with $<25$ insertions compared to those performed by operators with $>25$ insertions $(25.2 \%$ vs $13.6 \%, P=.04$ ), highlighting the need for improved training and supervision of inexperienced operators. Two significant predictors of increased risk for procedure-related complications were limited experience ( $<25$ previous CVC insertions) and insertion in the subclavian vein. ${ }^{54}$

\section{We suggest using either a transverse (short-axis) or lon- gitudinal (long-axis) approach when performing real-time ultrasound-guided vascular access procedures.}

Rationale: In clinical practice, the phrases transverse, short-axis, or out-of-plane approach are synonymous, as are longitudinal, long-axis, and in-plane approach. The short-axis approach involves tracking the needle tip as it approximates the target vessel with the ultrasound beam oriented in a transverse plane perpendicular to the target vessel. The target vessel is seen as a circular structure on the ultrasound screen as the needle tip approaches the target vessel from above. This approach is also called the out-of-plane technique since the needle passes through the ultrasound plane. The advantages of the short-axis approach include better visualization of adjacent vessels or nerves and the relative ease of skill acquisition for novice operators. ${ }^{9}$ When using the short-axis approach, extra care must be taken to track the needle tip from the point of insertion on the skin to the target vessel. A disadvantage of the short-axis approach is unintended posterior wall puncture of the target vessel. ${ }^{55}$

In contrast to a short-axis approach, a long-axis approach is performed with the ultrasound beam aligned parallel to the vessel. The vessel appears as a long tubular structure and the entire needle is visualized as it traverses across the ultrasound screen to approach the target vessel. The long-axis approach is also called an in-plane technique because the needle is maintained within the plane of the ultrasound beam. The advantage of a long-axis approach is the ability to visualize the entire needle as it is inserted into the vessel. ${ }^{14} \mathrm{~A}$ randomized crossover study with simulation models compared a long-axis versus short-axis approach for both IJV and subclavian vein catheterization. This study showed decreased number of needle redirections (relative risk (RR) 0.5, 95\% confidence interval (CI) 0.3 to 0.7 ), and posterior wall penetrations (OR 0.3, 95\% $\mathrm{Cl} 0.1$ to 0.9 ) using a long-axis versus short-axis approach for subclavian vein catheterization. ${ }^{56}$
A randomized controlled study comparing a long-axis or short-axis approach with ultrasound versus a landmark-based approach for IJV CVC insertion showed higher success rates (100\% vs 90\%; $P<.001$ ), lower insertion time (53 vs 116 seconds; $P<.001$ ), and fewer attempts to obtain access ( 2.5 vs 1.2 attempts, $P<.001$ ) with either the long- or short-axis ultrasound approach. The average time to obtain access and number of attempts were comparable between the short-axis and long-axis approaches with ultrasound. The incidence of carotid puncture and hematoma was significantly higher with the landmark-based approach versus either the long- or short-axis ultrasound approach (carotid puncture 17\% vs $3 \%$, $P=.024$; hematoma $23 \%$ vs $3 \%, P=.003) . .^{57}$

High success rates have been reported using a short-axis approach for insertion of PIV lines. ${ }^{58}$ A prospective, randomized trial compared the short-axis and long-axis approach in patients who had had $\geq 2$ failed PIV insertion attempts. Success rate was $95 \%$ (95\% Cl, 0.85 to 1.00$)$ in the short-axis group compared with $85 \%(95 \% \mathrm{Cl}, 0.69$ to 1.00$)$ in the long-axis group. All three subjects with failed PIV placement in the long-axis group had successful rescue placement using a short-axis approach. Furthermore, the short-axis approach was faster than the long-axis approach..$^{59}$

For radial artery cannulation, limited data exist comparing the short- and long-axis approaches. A randomized controlled study compared a long-axis vs short-axis ultrasound approach for radial artery cannulation. Although the overall procedure success rate was $100 \%$ in both groups, the long-axis approach had higher first-pass success rates $(1.27 \pm 0.4$ vs $1.5 \pm 0.5, P<$ .05), shorter cannulation times ( $24 \pm 17$ vs $47 \pm 34$ seconds, $P<$ .05), fewer hematomas ( $4 \%$ vs $43 \%, P<.05$ ) and fewer posterior wall penetrations $(20 \%$ vs $56 \%, P<.05) .60$

Another technique that has been described for IJV CVC insertion is an oblique-axis approach, a hybrid between the longand short-axis approaches. In this approach, the transducer is aligned obliquely over the IJV and the needle is inserted using a long-axis or in-plane approach. A prospective randomized trial compared the short-axis, long-axis, and oblique-axis approaches during IJV cannulation. First-pass success rates were $70 \%, 52 \%$, and $74 \%$ with the short-axis, long-axis, and oblique-axis approaches, respectively, and a statistically significant difference was found between the long- and oblique-axis approaches ( $P=.002$ ). A higher rate of posterior wall puncture was observed with a short-axis approach (15\%) compared with the oblique-axis (7\%) and long-axis (4\%) approaches $(P=$ .047). ${ }^{61}$

\section{We recommend that providers should visualize the needle tip and guidewire in the target vein prior to vessel dilatation.}

Rationale: When real-time ultrasound guidance is used, visualization of the needle tip within the vein is the first step to confirm cannulation of the vein and not the artery. After the guidewire is advanced, the provider can use transverse and longitudinal views to reconfirm cannulation of the vein. In 
a longitudinal view, the guidewire is readily seen positioned within the vein, entering the anterior wall and lying along the posterior wall of the vein. Unintentional perforation of the posterior wall of the vein with entry into the underlying artery can be detected by ultrasound, allowing prompt removal of the needle and guidewire before proceeding with dilation of the vessel. In a prospective observational study that reviewed ultrasound-guided IJV CVC insertions, physicians were able to more readily visualize the guidewire than the needle in the vein. ${ }^{62}$ A prospective observational study determined that novice operators can visualize intravascular guidewires in simulation models with an overall accuracy of $97 \% .{ }^{63}$

In a retrospective review of CVC insertions where the guidewire position was routinely confirmed in the target vessel prior to dilation, there were no cases of arterial dilation, suggesting confirmation of guidewire position can potentially eliminate the morbidity and mortality associated with arterial dilation during CVC insertion. ${ }^{64}$

\section{To increase the success rate of ultrasound-guided vas- cular access procedures, we recommend that providers should utilize echogenic needles, plastic needle guides, and/or ultrasound beam steering when available.}

Rationale: Echogenic needles have ridged tips that appear brighter on the screen, allowing for better visualization of the needle tip. Plastic needle guides help stabilize the needle alongside the transducer when using either a transverse or longitudinal approach. Although evidence is limited, some studies have reported higher procedural success rates when using echogenic needles, plastic needle guides, and ultrasound beam steering software. In a prospective observational study, Augustides et al. showed significantly higher IJV cannulation rates with versus without use of a needle guide after first (81\% vs $69 \%, P=.0054)$ and second $(93 \%$ vs $80 \% . P=.0001)$ needle passes. ${ }^{65}$ A randomized study by Maecken et al. compared subclavian vein CVC insertion with or without use of a needle guide, and found higher procedure success rates within the first and second attempts, reduced time to obtain access (16 seconds vs 30 seconds; $P=.0001)$ and increased needle visibility $\left(86 \%\right.$ vs $32 \% ; P<.0001$ ) with the use of a needle guide. ${ }^{66} \mathrm{An}-$ other study comparing a short-axis versus long-axis approach with a needle guide showed improved needle visualization using a long-axis approach with a needle guide. ${ }^{67} \mathrm{~A}$ randomized study comparing use of a novel, sled-mounted needle guide to a free-hand approach for venous cannulation in simulation models showed the novel, sled-mounted needle guide improved overall success rates and efficiency of cannulation. ${ }^{68}$

\section{Central Venous Access Techniques}

10. We recommend that providers should use a standardized procedure checklist that includes use of real-time ultrasound guidance to reduce the risk of central line-associated bloodstream infection (CLABSI) from CVC insertion.
Rationale: A standardized checklist or protocol should be developed to ensure compliance with all recommendations for insertion of CVCs. Evidence-based protocols address periprocedural issues, such as indications for CVC, and procedural techniques, such as use of maximal sterile barrier precautions to reduce the risk of infection. Protocols and checklists that follow established guidelines for CVC insertion have been shown to decrease CLABSI rates. ${ }^{69,70}$ Similarly, development of checklists and protocols for maintenance of central venous catheters have been effective in reducing CLABSIs. ${ }^{71}$ Although no externally-validated checklist has been universally accepted or endorsed by national safety organizations, a few internally-validated checklists are available through peer-reviewed publications. ${ }^{72,73}$ An observational educational cohort of internal medicine residents who received training using simulation of the entire CVC insertion process was able to demonstrate fewer CLABSIs after the simulator-trained residents rotated in the intensive care unit (ICU) (0.50 vs 3.2 infections per 1,000 catheter days, $\mathrm{P}=.001) .{ }^{74}$

\section{We recommend that providers should use real-time ultrasound guidance, combined with aseptic technique and maximal sterile barrier precautions, to reduce the incidence of infectious complications from CVC insertion.}

Rationale: The use of real-time ultrasound guidance for CVC placement has demonstrated a statistically significant reduction in CLABSIs compared to landmark-based techniques. ${ }^{75}$ The Centers for Disease Control and Prevention (CDC) guidelines for the prevention of intravascular catheter-related infections recommend the use of ultrasound guidance to reduce the number of cannulation attempts and risk of mechanical complications. ${ }^{69} \mathrm{~A}$ prospective, three-arm study comparing ultrasound-guided long-axis, short-axis, and landmark-based approaches showed a CLABSI rate of $20 \%$ in the landmark-based group versus $10 \%$ in each of the ultrasound groups. ${ }^{57}$ Another randomized study comparing use of ultrasound guidance to a landmark-based technique for IJV CVC insertion demonstrated significantly lower CLABSI rates with the use of ultrasound $(2 \%$ vs $10 \% ; P<.05) .^{72}$

Studies have shown that a systems-based intervention featuring a standardized catheter kit or catheter bundle significantly reduced CLABSI rates. ${ }^{76-78}$ A complete review of all preventive measures to reduce the risk of CLABSI is beyond the scope of this review, but a few key points will be mentioned. First, aseptic technique includes proper hand hygiene and skin sterilization, which are essential measures to reduce cutaneous colonization of the insertion site and reduce the risk of CLABSIs. ${ }^{79}$ In a systematic review and meta-analysis of eight studies including over 4,000 catheter insertions, skin antisepsis with chlorhexidine was associated with a $50 \%$ reduction in CLABSIs compared with povidone iodine. ${ }^{11}$ Therefore, a chlorhexidine-containing solution is recommended for skin preparation prior to CVC insertion per guidelines by Healthcare Infection Control Practices Advisory Committee/CDC, Society for Healthcare Epidemiology of America/Infectious Diseases 
Society of America, and American Society of Anesthesiologists. ${ }^{11,69,80,81}$ Second, maximal sterile barrier precautions refer to the use of sterile gowns, sterile gloves, caps, masks covering both the mouth and nose, and sterile full-body patient drapes. Use of maximal sterile barrier precautions during CVC insertion has been shown to reduce the incidence of CLABSIs compared to standard precautions. ${ }^{26,79,82-84}$ Third, catheters containing antimicrobial agents may be considered for hospital units with higher CLABSI rates than institutional goals, despite a comprehensive preventive strategy, and may be considered in specific patient populations at high risk of severe complications from a CLABSI. ${ }^{11,69,80}$ Finally, providers should use a standardized procedure set-up when inserting CVCs to reduce the risk of CLABSIs. The operator should confirm availability and proper functioning of ultrasound equipment prior to commencing a vascular access procedure. Use of all-inclusive procedure carts or kits with sterile ultrasound probe covers, sterile gel, catheter kits, and other necessary supplies is recommended to minimize interruptions during the procedure, and can ultimately reduce the risk of CLABSIs by ensuring maintenance of a sterile field during the procedure. ${ }^{13}$

\section{We recommend that providers should use real-time ultrasound guidance for internal jugular vein catheteriza- tion, which reduces the risk of mechanical and infectious complications, the number of needle passes, and time to cannulation and increases overall procedure success rates.}

Rationale: The use of real-time ultrasound guidance for CVC insertion has repeatedly demonstrated better outcomes compared to a landmark-based approach in adults. ${ }^{13}$ Several randomized controlled studies have demonstrated that real-time ultrasound guidance for IJV cannulation reduces the risk of procedure-related mechanical and infectious complications, and improves first-pass and overall success rates in diverse care settings. $27,29,45,50,53,65,75,85-90$ Mechanical complications that are reduced with ultrasound guidance include pneumothorax and carotid artery puncture. ${ }^{4,5,45,46,53,62,75,86-93}$ Currently, several medical societies strongly recommend the use of ultrasound guidance during insertion of IJV CVCs. ${ }^{10-12,14,94-96}$

A meta-analysis by Hind et al. that included 18 randomized controlled studies demonstrated use of real-time ultrasound guidance reduced failure rates (RR $0.14,95 \% \mathrm{Cl} 0.06$ to 0.33 ; $P<.0001$ ), increased first-attempt success rates (RR 0.59, 95\% $\mathrm{Cl} 0.39$ to $0.88 ; P=.009$ ), reduced complication rates (RR 0.43, $95 \% \mathrm{Cl} 0.22$ to $0.87 ; P=.02)$ and reduced procedure time ( $P$ $<.0001)$, compared to a traditional landmark-based approach when inserting IJV CVCs. ${ }^{5}$

A Cochrane systematic review compared ultrasound-guided versus landmark-based approaches for IJV CVC insertion and found use of real-time ultrasound guidance reduced total complication rates by $71 \%$ (RR $0.29,95 \% \mathrm{Cl} 0.17$ to $0.52 ; P<$ .0001 ), arterial puncture rates by $72 \%$ (RR $0.28,95 \% \mathrm{Cl} 0.18$ to $0.44 ; P<.00001)$, and rates of hematoma formation by $73 \%$ (RR $0.27,95 \% \mathrm{Cl} 0.13$ to $0.55 ; P=.0004)$. Furthermore, the num- ber of attempts for successful cannulation was reduced (mean difference -1.19 attempts, $95 \% \mathrm{Cl}-1.45$ to $-0.92 ; P<.00001)$, the chance of successful insertion on the first attempt was increased by $57 \%$ (RR $1.57,95 \% \mathrm{Cl} 1.36$ to $1.82 ; P<.00001)$, and overall procedure success rates were modestly increased in all groups by $12 \%$ (RR $1.12,95 \% \mathrm{Cl} 1.08$ to $1.17 ; P<.00001) .{ }^{46}$

An important consideration in performing ultrasound guidance is provider experience. A prospective observational study of patients undergoing elective CVC insertion demonstrated higher complication rates for operators that were inexperienced (25.2\%) versus experienced (13.6\%). ${ }^{54} \mathrm{~A}$ randomized controlled study comparing experts and novices with or without the use of ultrasound guidance for IJV CVC insertion demonstrated higher success rates among expert operators and with the use of ultrasound guidance. Among novice operators, the complication rates were lower with the use of ultrasound guidance. ${ }^{97}$ One study evaluated the procedural success and complication rates of a two-physician technique with one physician manipulating the transducer and another inserting the needle for IJV CVC insertion. This study concluded that procedural success rates and frequency of complications were directly affected by the experience of the physician manipulating the transducer and not by the experience of the physician inserting the needle. ${ }^{98}$

The impact of ultrasound guidance on improving procedural success rates and reducing complication rates is greatest in patients that are obese, short necked, hypovolemic, or uncooperative. ${ }^{93}$ Several studies have demonstrated fewer needle passes and decreased time to cannulation compared to the landmark technique in these populations. ${ }^{46,49,53,86-88,92,93}$

Ultrasound-guided placement of IJV catheters can safely be performed in patients with disorders of hemostasis and those with multiple previous catheter insertions in the same vein. ${ }^{9} \mathrm{Ul}-$ trasound-guided placement of CVCs in patients with disorders of hemostasis is safe with high success and low complication rates. In a case series of liver patients with coagulopathy (mean INR $2.17 \pm 1.16$, median platelet count 150K), the use of ultrasound guidance for CVC insertion was highly successful with no major bleeding complications. ${ }^{99}$

A study of renal failure patients found high success rates and low complication rates in the patients with a history of multiple previous catheterizations, poor compliance, skeletal deformities, previous failed cannulations, morbid obesity, and disorders of hemostasis. ${ }^{100}$ A prospective observational study of 200 ultrasound-guided CVC insertions for apheresis showed a $100 \%$ success rate with a $92 \%$ first-pass success rate. ${ }^{101}$

The use of real-time ultrasound guidance for IJV CVC insertion has been shown to be cost effective by reducing procedure-related mechanical complications and improving procedural success rates. A companion cost-effectiveness analysis estimated that for every 1,000 patients, 90 complications would be avoided, with a net cost savings of approximately $\$ 3,200$ using 2002 prices. ${ }^{102}$

13. We recommend that providers who routinely insert subclavian vein CVCs should use real-time ultrasound guidance, which has been shown to reduce the risk of 
mechanical complications and number of needle passes and increase overall procedure success rates compared with landmark-based techniques.

Rationale: In clinical practice, the term ultrasound-guided subclavian vein CVC insertion is commonly used. However, the needle insertion site is often lateral to the first rib and providers are technically inserting the CVC in the axillary vein. The subclavian vein becomes the axillary vein at the lateral border of the first rib where the cephalic vein branches from the subclavian vein. To be consistent with common medical parlance, we use the phrase ultrasound-guided subclavian vein CVC insertion in this document.

Advantages of inserting CVCs in the subclavian vein include reliable surface anatomical landmarks for vein location, patient comfort, and lower risk of infection. ${ }^{103}$ Several observational studies have demonstrated the technique for ultrasound-guided subclavian vein CVC insertion is feasible and safe. ${ }^{104-107}$ In a large retrospective observational study of ultrasound-guided central venous access among a complex patient group, the majority of patients were cannulated successfully and safely. The subset of patients undergoing axillary vein CVC insertion ( $n=$ $1,923)$ demonstrated a low rate of complications $(0.7 \%)$, proving it is a safe and effective alternative to the IJV CVC insertion. ${ }^{107}$

A Cochrane review of ultrasound-guided subclavian vein cannulation (nine studies, 2,030 participants, 2,049 procedures), demonstrated that real-time two-dimensional ultrasound guidance reduced the risk of inadvertent arterial punctures (three studies, 498 participants, RR $0.21,95 \% \mathrm{Cl} 0.06$ to $0.82 ; P=.02$ ) and hematoma formation (three studies, 498 participants, RR $0.26,95 \% \mathrm{Cl} 0.09$ to $0.76 ; P=.01) .{ }^{46} \mathrm{~A}$ systematic review and meta-analysis of 10 randomized controlled studies comparing ultrasound-guided versus landmark-based subclavian vein $\mathrm{CVC}$ insertion demonstrated a reduction in the risk of arterial punctures, hematoma formation, pneumothorax, and failed catheterization with the use of ultrasound guidance. ${ }^{105}$

A randomized controlled study comparing ultrasound-guided vs landmark-based approaches to subclavian vein cannulation found that use of ultrasound guidance had a higher success rate ( $92 \%$ vs $44 \%, P=.0003)$, fewer minor complications ( 1 vs $11, P=.002$ ), fewer attempts (1.4 vs $2.5, P=.007$ ) and fewer catheter kits used (1.0 vs $1.4, P=.0003$ ) per cannulation. ${ }^{108}$

Fragou et al. randomized patients undergoing subclavian vein CVC insertion to a long-axis approach versus a landmark-based approach and found a significantly higher success rate $(100 \%$ vs $87.5 \%, P<.05)$ and lower rates of mechanical complications: artery puncture (0.5\% vs $5.4 \%)$, hematoma $(1.5 \%$ vs $5.4 \%)$, hemothorax (0\% vs $4.4 \%)$, pneumothorax $(0 \%$ vs $4.9 \%)$, brachial plexus injury (0\% vs $2.9 \%)$, phrenic nerve injury $(0 \%$ vs $1.5 \%)$, and cardiac tamponade ( $0 \%$ vs $0.5 \%) .{ }^{109}$ The average time to obtain access and the average number of insertion attempts $(1.1 \pm 0.3$ vs $1.9 \pm 0.7, P<.05)$ were significantly reduced in the ultrasound group compared to the landmark-based group. ${ }^{95}$

A retrospective review of subclavian vein CVC insertions using a supraclavicular approach found no reported compli- cations with the use of ultrasound guidance vs 23 mechanical complications (8 pneumothorax, 15 arterial punctures) with a landmark-based approach. ${ }^{106}$ However, it is important to note that a supraclavicular approach is not commonly used in clinical practice.

\section{We recommend that providers should use real-time} ultrasound guidance for femoral venous access, which has been shown to reduce the risk of arterial punctures and total procedure time and increase overall procedure success rates.

Rationale: Anatomy of the femoral region varies, and close proximity or overlap of the femoral vein and artery is common. ${ }^{51}$ Early studies showed that ultrasound guidance for femoral vein CVC insertion reduced arterial punctures compared with a landmark-based approach (7\% vs $16 \%$ ), reduced total procedure time (55 \pm 19 vs $79 \pm 62$ seconds), and increased procedure success rates (100\% vs $90 \%) .{ }^{52} \mathrm{~A}$ Cochrane review that pooled data from four randomized studies comparing ultrasound-guided vs landmark-based femoral vein CVC insertion found higher first-attempt success rates with the use of ultrasound guidance (RR $1.73,95 \% \mathrm{Cl} 1.34$ to $2.22 ; P<.0001$ ) and a small increase in the overall procedure success rates (RR $1.11,95 \% \mathrm{Cl} 1.00$ to $1.23 ; P=.06$ ). There was no difference in inadvertent arterial punctures or other complications. ${ }^{110}$

\section{Peripheral Venous Access Techniques}

15. We recommend that providers should use real-time ultrasound guidance for the insertion of peripherally inserted central catheters (PICCs), which is associated with higher procedure success rates and may be more cost effective compared with landmark-based techniques.

Rationale: Several studies have demonstrated that providers who use ultrasound guidance vs landmarks for PICC insertion have higher procedural success rates, lower complication rates, and lower total placement costs. A prospective observational report of 350 PICC insertions using ultrasound guidance reported a $99 \%$ success rate with an average of 1.2 punctures per insertion and lower total costs. ${ }^{20} \mathrm{~A}$ retrospective observational study of $500 \mathrm{PICC}$ insertions by designated specialty nurses revealed an overall success rate of $95 \%$, no evidence of phlebitis, and only one CLABSI among the catheters removed. ${ }^{21} \mathrm{~A}$ retrospective observational study comparing several PICC variables found higher success rates (99\% vs $77 \%$ ) and lower thrombosis rates ( $2 \%$ vs $9 \%$ ) using ultrasound guidance vs landmarks alone. ${ }^{22} \mathrm{~A}$ study by Robinson et al. demonstrated that having a dedicated PICC team equipped with ultrasound increased their institutional insertion success rates from $73 \%$ to $94 \% .{ }^{111}$

A randomized controlled study comparing ultrasound-guided versus landmark-based PICC insertion found high success rates with both techniques (100\% vs $96 \%$ ). However, there was a reduction in the rate of unplanned catheter removals $(4.0 \%$ vs $18.7 \% ; P=.02)$, mechanical phlebitis $(0 \%$ vs $22.9 \% ; P<.001)$, 
and venous thrombosis ( $0 \%$ vs $8.3 \% ; P=.037)$, but a higher rate of catheter migration ( $32 \%$ vs $2.1 \%$; $P<.001)$. Compared with the landmark-based group, the ultrasound-guided group had significantly lower incidence of severe contact dermatitis $(P=$ .038), and improved comfort and costs up to 3 months after PICC placement $(P<.05) .{ }^{112}$

Routine postprocedure chest $x$-ray $(C X R)$ is generally considered unnecessary if the PICC is inserted with real-time ultrasound guidance along with use of a newer tracking devices, like the magnetic navigation system with intracardiac electrodes. ${ }^{9}$ Ultrasound can also be used to detect malpositioning of a PICC immediately after completing the procedure. A randomized controlled study comparing ultrasound versus postprocedure CXR detected one malpositioned PICC in the ultrasound group versus 11 in the control group. This study suggested that ultrasound can detect malpositioning immediately postprocedure and reduce the need for a CXR and the possibility of an additional procedure to reposition a catheter. ${ }^{113}$

\section{We recommend that providers should use real-time ultrasound guidance for the placement of peripheral intravenous lines (PIV) in patients with difficult peripheral venous access to reduce the total procedure time, nee- dle insertion attempts, and needle redirections. Ultra- sound-guided PIV insertion is also an effective alternative to CVC insertion in patients with difficult venous access.}

Rationale: Difficult venous access refers to patients that have had two unsuccessful attempts at PIV insertion using landmarks or a history of difficult access (i.e. edema, obesity, intravenous drug use, chemotherapy, diabetes, hypovolemia, chronic illness, vasculopathy, multiple prior hospitalizations). A meta-analysis of seven randomized controlled studies concluded that ultrasound guidance increases the likelihood of successful PIV insertion (pooled OR 2.42, 95\% Cl 1.26 to 4.68; P $<$.008). $18 \mathrm{~A}$ second meta-analysis that pooled data from seven studies (six randomized controlled studies) confirmed that ultrasound guidance improves success rates of PIV insertion (OR 3.96, 95\% Cl 1.75 to 8.94).19 Approximately half of these studies had physician operators while the other half had nurse operators.

In one prospective observational study of emergency department patients with two failed attempts of landmark-based PIV insertion, ultrasound guidance with a modified-Seldinger technique showed a relatively high success rate (96\%), fewer needle sticks (mean 1.32 sticks, $95 \% \mathrm{Cl} 1.12$ to 1.52), and shorter time to obtain access (median time 68 seconds). ${ }^{114}$ Other prospective observational studies have demonstrated that ultrasound guidance for PIV insertion has a high success rate (87\%), ${ }^{115}$ particularly with brachial or basilic veins PIV insertion, among patients with difficult PIV access, defined as having had $\geq 2$ failed attempts. ${ }^{58}$

Since insertion of PIVs with ultrasound guidance has a high success rate, there is potential to reduce the reliance on CVC insertion for venous access only. In a study of patients that had had two failed attempts at PIV insertion based on landmarks, a
PIV was successfully inserted with ultrasound guidance in $84 \%$ of patients, obviating the need for CVC placement for venous access. ${ }^{116}$ A prospective observational study showed ultrasound-guided PIV insertion was an effective alternative to CVC placement in ED patients with difficult venous access with only $1 \%$ of patients requiring a CVC. ${ }^{117}$ Use of ultrasound by nurses for PIV placement has also been shown to reduce the time to obtain venous access, improve patient satisfaction, and reduce the need for physician intervention. ${ }^{118}$ In a prospective observational study of patients with difficult access, the majority of patients reported a better experience with ultrasound-guided PIV insertion compared to previous landmark-based attempts with an average satisfaction score of $9.2 / 10$ with $76 \%$ of patients rating the experience a $10 .{ }^{119} \mathrm{~A}$ strong recommendation has been made for use of ultrasound guidance in patients with difficult PIV placement by la Société Française d'Anesthésie et de Réanimation (The French Society of Anesthesia and Resuscitation). ${ }^{95}$

17. We suggest using real-time ultrasound guidance to reduce the risk of vascular, infectious, and neurological complications during PIV insertion, particularly in patients with difficult venous access.

Rationale: The incidence of complications from PIV insertion is often underestimated. Vascular complications include arterial puncture, hematoma formation, local infiltration or extravasation of fluid, and superficial or deep venous thrombosis. The most common infectious complications with PIV insertion are phlebitis and cellulitis. ${ }^{120}$ One observational study reported PIV complications occurring in approximately half of all patients with the most common complications being phlebitis, hematoma formation, and fluid/blood leakage. ${ }^{121}$

A retrospective review of ICU patients who underwent ultrasound-guided PIV insertion by a single physician showed high success rates (99\%) with low rates of phlebitis/cellulitis $(0.7 \%)$. There was an assumed benefit of risk reduction due to the patients no longer requiring a CVC after successful PIV placement. ${ }^{122}$ Another study found very low rates of infection with both landmark-based and ultrasound-guided PIV placement performed by emergency department nurses, suggesting that there is no increased risk of infection with the use of ultrasound. ${ }^{123}$ To reduce the risk of infection from PIV insertion, we recommend the use of sterile gel and sterile transducer cover (See Recommendation 2).

\section{Arterial Access Techniques}

18. We recommend that providers should use real-time ultrasound guidance for arterial access, which has been shown to increase first-pass success rates, reduce the time to cannulation, and reduce the risk of hematoma development compared with landmark-based techniques.

Rationale: Several randomized controlled studies have assessed the value of ultrasound in arterial catheter insertion. Shiver et al. randomized 60 patients admitted to a tertiary 
center emergency department to either palpation or ultrasound-guided arterial cannulation. They demonstrated a firstpass success rate of $87 \%$ in the ultrasound group compared with $50 \%$ in the landmark technique group. In the same study, the use of ultrasound was also associated with reduced time needed to establish arterial access and a $43 \%$ reduction in the development of hematoma at the insertion site. ${ }^{124}$ Levin et al. demonstrated a first-pass success rate of $62 \%$ using ultrasound versus $34 \%$ by palpation alone in 69 patients requiring intraoperative invasive hemodynamic monitoring. ${ }^{125}$ Additional randomized controlled studies have demonstrated that ultrasound guidance increases first-attempt success rates compared to traditional palpation. ${ }^{23,126,127}$

\section{We recommend that providers should use real-time ultrasound guidance for femoral arterial access, which has been shown to increase first-pass success rates and reduce the risk of vascular complications.}

Rationale: Although it is a less frequently used site, the femoral artery may be accessed for arterial blood sampling or invasive hemodynamic monitoring, and use of ultrasound guidance has been shown to improve the first-pass success rates of femoral artery cannulation. It is important to note that most of these studies comparing ultrasound-guided vs landmark-based femoral artery cannulation were performed in patients undergoing diagnostic or interventional vascular procedures.

A meta-analysis of randomized controlled studies comparing ultrasound-guided vs landmark-based femoral artery catheterization found use of ultrasound guidance was associated with a $49 \%$ reduction in overall complications (RR 0.51, $95 \% \mathrm{Cl} 0.28$ to $0.91 ; P>.05$ ) and $42 \%$ improvement in firstpass success rates. ${ }^{128}$ In another study, precise site selection with ultrasound was associated with fewer pseudoaneurysms in patients undergoing femoral artery cannulation by ultrasound guidance vs palpation for cardiac catheterization (3\% vs $5 \%, P<.05) .{ }^{129}$

A multicenter randomized controlled study comparing ultrasound vs fluoroscopic guidance for femoral artery catheterization demonstrated ultrasound guidance improved rates of common femoral artery (CFA) cannulation in patients with high CFA bifurcations (83\% vs 70\%, $P<.01) .{ }^{130}$ Furthermore, ultrasound guidance improved first-pass success rates $(83 \%$ vs $46 \%, P<.0001)$, reduced number of attempts (1.3 vs 3.0, $P<$ $.0001)$, reduced risk of venipuncture $(2.4 \%$ vs $15.8 \%, P<.0001)$, and reduced median time to obtain access (136 seconds vs148 seconds, $P=.003$ ). Vascular complications occurred in fewer patients in the ultrasound vs fluoroscopy groups (1.4\% vs $3.4 \%$ $P=.04)$. Reduced risk of hematoma formation with routine use of ultrasound guidance was demonstrated in one retrospective observational study (RR $0.62,95 \% \mathrm{Cl} 0.46$ to $0.84 ; P<.01$ ). ${ }^{131}$

20. We recommend that providers should use real-time ultrasound guidance for radial arterial access, which has been shown to increase first-pass success rates, reduce the time to successful cannulation, and reduce the risk of complications compared with landmark-based techniques.

Rationale: Ultrasound guidance is particularly useful for radial artery cannulation in patients with altered anatomy, obesity, nonpulsatile blood flow, low perfusion, and previously unsuccessful cannulation attempts using a landmark-guided approach. ${ }^{132}$ A meta-analysis of six randomized controlled studies in adults showed that use of ultrasound guidance significantly increased first-attempt success rate of radial artery catheterization by $14-37 \%$ (RR $1.4,95 \% \mathrm{Cl} 1.28$ to $1.64 ; P<.00001$ ), reduced mean number of attempts (weighted mean difference (WMD) $-1.17 ; 95 \% \mathrm{Cl}-2.21$ to $-0.13 ; P=.03$ ), and mean time to successful cannulation (WMD -46 seconds; $95 \% \mathrm{Cl}-86.66$ to $-5.96, P=.02) .{ }^{133}$ Other meta-analyses of randomized studies have demonstrated similar benefits of using ultrasound guidance for radial artery cannulation. ${ }^{126,127,134}$

A multicenter randomized controlled study that was not included in the abovementioned meta-analyses showed similar benefits of using ultrasound guidance vs landmarks for radial artery catheterization: a reduction in the number of attempts with ultrasound guidance (1.65 \pm 1.2 vs $3.05 \pm 3.4, P<.0001)$ and time to obtain access ( $88 \pm 78$ vs $108 \pm 112$ seconds, $P$ $=.006$ ), and increased first-pass success rates (65\% vs $44 \%$, $P<.0001)$. The use of ultrasound guidance was found to be particularly useful in patients with difficult access by palpation alone. ${ }^{135}$

Regarding the level of expertise required to use ultrasound guidance, a prospective observational study demonstrated that physicians with little previous ultrasound experience were able to improve their first-attempt success rates and procedure time for radial artery cannulation compared to historical data of landmark-based insertions. ${ }^{136}$

\section{Postprocedure}

21. We recommend that post-procedure pneumothorax should be ruled out by the detection of bilateral lung sliding using a high-frequency linear transducer before and after insertion of internal jugular and subclavian vein CVCs.

Rationale: Detection of lung sliding with two-dimensional ultrasound rules out pneumothorax, and disappearance of lung sliding in an area where it was previously seen is a strong predictor of postprocedure pneumothorax. In a study of critically ill patients, the disappearance of lung sliding was observed in $100 \%$ of patients with pneumothorax vs $8.8 \%$ of patients without pneumothorax. For detection of pneumothorax, lung sliding showed a sensitivity of $95 \%$, specificity of $91 \%$, and negative predictive value of $100 \%(P<.001) .{ }^{137}$ Another study by the same author showed that the combination of horizontal artifacts (absence of comet-tail artifact) and absence of lung sliding had a sensitivity of $100 \%$, specificity of $96.5 \%$, and negative predictive value of $100 \%$ for the detection of pneumothorax. ${ }^{138}$ A meta-analysis of 10 studies on the diagnostic ac- 
curacy of CVC confirmation with bedside ultrasound vs chest radiography reported detection of all 12 pneumothoraces with ultrasound, whereas chest radiography missed two pneumothoraces. The pooled sensitivity and specificity of ultrasound for the detection of pneumothorax was 100\%, although an imperfect gold standard bias likely affected the results. An important advantage of bedside ultrasound is the ability to rule out pneumothorax immediately after the procedure while at the bedside. The mean time for confirmation of CVC placement with bedside ultrasound was 6 minutes versus 64 minutes and 143 minutes for completion and interpretation of a chest radiograph, respectively. ${ }^{139}$

\section{We recommend that providers should use ultrasound with rapid infusion of agitated saline to visualize a right atrial swirl sign (RASS) for detecting catheter tip misplace- ment during CVC insertion. The use of RASS to detect the catheter tip may be considered an advanced skill that requires specific training and expertise.}

Rationale: Bedside echocardiography is a reliable tool to detect catheter tip misplacement during CVC insertion. In one study, catheter misplacement was detected by bedside echocardiography with a sensitivity of $96 \%$ and specificity of $83 \%$ (positive predictive value $98 \%$, negative predictive value $55 \%$ ) and prevented distal positioning of the catheter tip. ${ }^{140}$ A prospective observational study assessed for RASS, which is turbulent flow in the right atrium after a rapid saline flush of the distal CVC port, to exclude catheter malposition. In this study with 135 CVC placements, visualization of RASS with ultrasound was able to identify all correct CVC placements and three of four catheter misplacements. Median times to complete the ultrasound exam vs CXR were 1 vs 20 minutes, respectively, with a median difference of 24 minutes $(95 \% \mathrm{Cl} 19.6$ to $29.3, P<.0001)$ between the two techniques. ${ }^{141}$

A prospective observational study assessed the ability of bedside transthoracic echocardiography to detect the guidewire, microbubbles, or both, in the right atrium compared to transesophageal echocardiography as the gold standard. Bedside transthoracic echocardiography allowed visualization of the right atrium in $94 \%$ of patients, and both microbubbles plus guidewire in $91 \%$ of patients. ${ }^{142}$ Hence, bedside transthoracic echocardiography allows adequate visualization of the right atrium. Another prospective observational study combining ultrasonography and contrast enhanced RASS resulted in $96 \%$ sensitivity and $93 \%$ specificity for the detection of a misplaced catheter, and the concordance with chest radiography was $96 \% .^{143}$

\section{Training}

23. To reduce the risk of mechanical and infectious complications, we recommend that novice providers should complete a systematic training program that includes a combination of simulation-based practice, supervised insertion on patients, and evaluation by an expert operator before attempting ultrasound-guided CVC insertion independently on patients.

Rationale: Cumulative experience has been recognized to not be a proxy for mastery of a clinical skill. ${ }^{144}$ The National Institute for Clinical Excellence (NICE) has recommended that providers performing ultrasound-guided CVC insertion should receive appropriate training to achieve competence before performing the procedure independently. ${ }^{7}$ Surveys have demonstrated that lack of training is a commonly reported barrier for not using ultrasound. ${ }^{145,146}$

Structured training programs on CVC insertion have been shown to reduce the occurrence of infectious and mechanical complications. ${ }^{74,143,147-149}$ The use of ultrasound and checklists, bundling of supplies, and practice with simulation models, as a part of a structured training program, can improve patient safety related to CVC insertion. 9,140,150-154

Simulation-based practice has been used in medical education to provide deliberate practice and foster skill development in a controlled learning environment. ${ }^{155-158}$ Studies have shown transfer of skills demonstrated in a simulated environment to clinical practice, which can improve CVC insertion practices. ${ }^{159,160}$ Simulation accelerates learning of all trainees, especially novice trainees, and mitigates risks to patients by allowing trainees to achieve a minimal level of competence before attempting the procedure on real patients. ${ }^{152,161,162}$ Residents that have been trained using simulation preferentially select the IJV site, ${ }^{147}$ and more reliably use ultrasound to guide their CVC insertions. ${ }^{160,163}$

Additionally, simulation-based practice allows exposure to procedures and scenarios that may occur infrequently in clinical practice.

Although there is evidence on efficacy of simulation-based CVC training programs, there is no broadly accepted consensus on timing, duration, and content of CVC training programs for trainees or physicians in practice. The minimum recommended technical skills a trainee must master include the ability to (1) manipulate the ultrasound machine to produce a high-quality image to identify the target vessel, (2) advance the needle under direct visualization to the desired target site and depth, (3) deploy the catheter into the target vessel and confirm catheter placement in the target vessel using ultrasound, and (4) ensure the catheter has not been inadvertently placed in an unintended vessel or structure. ${ }^{153}$

A variety of simulation models are currently used to practice CVC insertion at the most common sites: the internal jugular, subclavian, basilic, and brachial veins. ${ }^{164,165}$ Effective simulation models should contain vessels that mimic normal anatomy with muscles, soft tissues, and bones. Animal tissue models, such as turkey or chicken breasts, may be effective for simulated practice of ultrasound-guided CVC insertion. ${ }^{166,167}$ Ultrasound-guided CVC training using human cadavers has also been shown to be effective. ${ }^{168}$

\section{We recommend that cognitive training in ultra- sound-guided CVC insertion should include basic anato-}


my, ultrasound physics, ultrasound machine knobology, fundamentals of image acquisition and interpretation, detection and management of procedural complications, infection prevention strategies, and pathways to attain competency.

Rationale: After receiving training in ultrasound-guided CVC insertion, physicians report significantly higher comfort with the use of ultrasound compared to those who have not received such training. ${ }^{145}$ Learners find training sessions worthwhile to increase skill levels, ${ }^{167}$ and skills learned from simulation-based mastery learning programs have been retained up to one year. ${ }^{158}$

Several commonalities have been noted across training curricula. Anatomy and physiology didactics should include vessel anatomy (location, size, and course); ${ }^{9}$ vessel differentiation by ultrasound; ;,69 blood flow dynamics; 69 Virchow's tri$\mathrm{ad}_{;}^{69}$ skin integrity and colonization; ${ }^{150}$ peripheral nerve identification and distribution; 9 respiratory anatomy; 9,69 upper and lower extremity, axillary, neck, and chest anatomy. 9.69 Vascular anatomy is an essential curricular component that may help avoid preventable CVC insertion complications, such as inadvertent nerve, artery, or lung puncture. 150,169 Training curricula should also include ultrasound physics (piezoelectric effect, frequency, resolution, attenuation, echogenicity, Doppler ultrasound, arterial and venous flow characteristics), image acquisition and optimization (imaging mode, focus, dynamic range, probe types), and artifacts (reverberation, mirror, shadowing, enhancement).

CVC-related infections are an important cause of morbidity and mortality in the acute and long-term care environment. ${ }^{69}$ Infection and thrombosis can both be impacted by the insertion site selection, skin integrity, and catheter-vein ratio. ${ }^{2,3,84}$ Inexperience generally leads to more insertion attempts that can increase trauma during CVC insertion and potentially increase the risk of infections. ${ }^{170}$ To reduce the risk of infectious complications, training should include important factors to consider in site selection and maintenance of a sterile environment during CVC insertion, including use of maximal sterile barrier precautions, hand hygiene, and appropriate use of skin antiseptic solutions.

Professional society guidelines have been published with recommendations of appropriate techniques for ultrasound-guided vascular access that include training recommendations. ${ }^{9,154}$ Training should deconstruct the insertion procedure into readily understood individual steps, and can be aided by demonstration of CVC insertion techniques using video clips. An alternative to face-to-face training is internet-based training that has been shown to be as effective as traditional teaching methods in some medical centers. ${ }^{171}$ Additional methods to deliver cognitive instruction include textbooks, continuing medical education courses, and digital videos. ${ }^{164,172}$

\section{We recommend that trainees should demonstrate minimal competence before placing ultrasound-guid- ed CVCs independently. A minimum number of CVC}

insertions may inform this determination, but a proctored assessment of competence is most important.

Rationale: CVC catheter placement carries the risk of serious complications including arterial injury or dissection, pneumothorax, or damage to other local structures; arrhythmias; catheter malposition; infection; and thrombosis. Although there is a lack of consensus and high-quality evidence for the certification of skills to perform ultrasound-guided CVC insertion, recommendations have been published advocating for formal and comprehensive training programs in ultrasound-guided CVC insertion with an emphasis on expert supervision prior to independent practice. 9,153,154 Two groups of expert operators have recommended that training should include at least 8-10 supervised ultrasound-guided CVC insertions. ${ }^{154,173,174}$ A consensus task force from the World Congress of Vascular Access has recommended a minimum of six to eight hours of didactic education, four hours of hands-on training on simulation models, and six hours of hands-on ultrasound training on human volunteers to assess normal anatomy. ${ }^{175}$ This training should be followed by supervised ultrasound-guided CVC insertions until the learner has demonstrated minimal competence with a low rate of complications. ${ }^{35}$ There is general consensus that arbitrary numbers should not be the sole determinant of competence, and that the most important determinant of competence should be an evaluation by an expert operator. ${ }^{176}$

\section{We recommend that didactic and hands-on training for trainees should coincide with anticipated times of increased performance of vascular access procedures. Refresher training sessions should be offered periodically.}

Rationale: Simulation-based CVC training courses have shown a rapid improvement in skills, but lack of practice leads to deterioration of technical skills. ${ }^{161,162,177,178}$ Thus, a single immersive training session is insufficient to achieve and maintain mastery of skills, and an important factor to acquire technical expertise is sustained, deliberate practice with feedback. ${ }^{179}$ Furthermore, an insidious decay in skills may go unrecognized as a learner's comfort and self-confidence does not always correlate with actual performance, leading to increased risk of errors and potential for procedural complications. ${ }^{147,158,180-183}$ Given the decay in technical skills over time, simulation-based training sessions are most effective when they occur in close temporal proximity to times when those skills are most likely to be used; for example, a simulation-based training session for trainees may be most effective just before the start of a critical care rotation. ${ }^{152}$ Regularly scheduled training sessions with monitoring and feedback by expert operators can reinforce procedural skills and prevent decay. Some experts have recommended that a minimum of 10 ultrasound-guided CVC insertions should be performed annually to maintain proficiency. ${ }^{153}$

27. We recommend that competency assessments should include formal evaluation of knowledge and technical skills using standardized assessment tools. 
Rationale: Hospitalists and other healthcare providers that place vascular access catheters should undergo competency assessments proctored by an expert operator to verify that they have the required knowledge and skills. ${ }^{184,185}$ Knowledge competence can be partially evaluated using a written assessment, such as a multiple-choice test, assessing the provider's cognitive understanding of the procedure. ${ }^{175}$ For ultrasound-guided CVC insertion, a written examination should be administered in conjunction with an ultrasound image assessment to test the learner's recognition of normal vs abnormal vascular anatomy. Minimum passing standards should be established a priori according to local or institutional standards.

The final skills assessment should be objective, and the learner should be required to pass all critical steps of the procedure. Failure of the final skills assessment should lead to continued practice with supervision until the learner can consistently demonstrate correct performance of all critical steps. Checklists are commonly used to rate the technical performance of learners because they provide objective criteria for evaluation, can identify specific skill deficiencies, and can determine a learner's readiness to perform procedures independently. ${ }^{186,187}$ The administration of skills assessments and feedback methods should be standardized across faculty. Although passing scores on both knowledge and skills assessments do not guarantee safe performance of a procedure independently, they provide a metric to ensure that a minimum level of competence has been achieved before allowing learners to perform procedures on patients without supervision. ${ }^{188}$

Competency assessments are a recommended component of intramural and extramural certification of skills in ultrasound-guided procedures. Intramural certification pathways differ by institution and often require additional resources including ultrasound machine(s), simulation equipment, and staff time, particularly when simulation-based assessments are incorporated into certification pathways. We recognize that some of these recommendations may not be feasible in resource-limited settings, such as rural hospitals. However, initial and ongoing competency assessments can be performed during routine performance of procedures on patients. For an in-depth review of credentialing pathways for ultrasound-guided bedside procedures, we recommend reviewing the SHM Position Statement on Credentialing of Hospitalists in Ultrasound-Guided Bedside Procedures. ${ }^{24}$

28. We recommend that competency assessments should evaluate for proficiency in the following knowledge and skills of CVC insertion:

a. Knowledge of the target vein anatomy, proper vessel identification, and recognition of anatomical variants

b. Demonstration of CVC insertion with no technical errors based on a procedural checklist

c. Recognition and management of acute complications, including emergency management of life-threatening complications

d. Real-time needle tip tracking with ultrasound and cannulation on the first attempt in at least five consecutive simulations.
Rationale: Recommendations have been published with the minimal knowledge and skills learners must demonstrate to perform ultrasound-guided vascular access procedures. These include operation of an ultrasound machine to produce high-quality images of the target vessel, tracking of the needle tip with real-time ultrasound guidance, and recognition and understanding of the management of procedural complications. ${ }^{154,175}$

First, learners must be able to perform a preprocedural assessment of the target vein, including size and patency of the vein; recognition of adjacent critical structures; and recognition of normal anatomical variants. ${ }^{175,189}$ Second, learners must be able to demonstrate proficiency in tracking the needle tip penetrating the target vessel, inserting the catheter into the target vessel, and confirming catheter placement in the target vessel with ultrasound. 154,175 Third, learners must be able to demonstrate recognition of acute complications, including arterial puncture, hematoma formation, and development of pneumothorax. ${ }^{154,175}$ Trainees should be familiar with recommended evaluation and management algorithms, including indications for emergent consultation. ${ }^{190}$

29. We recommend a periodic proficiency assessments of all operators should be conducted to ensure maintenance of competency.

Rationale: Competency extends to periodic assessment and not merely an initial evaluation at the time of training. ${ }^{191}$ Periodic competency assessments should include assessment of proficiency of all providers that perform a procedure, including instructors and supervisors. Supervising providers should maintain their competency in CVC insertion through routine use of their skills in clinical practice. ${ }^{175}$ An observational study of emergency medicine residents revealed that lack of faculty comfort with ultrasound hindered the residents' use of ultrasound. ${ }^{192}$ Thus, there is a need to examine best practices for procedural supervision of trainees because providers are often supervising procedures that they are not comfortable performing on their own. ${ }^{193}$

\section{KNOWLEDGE GAPS}

The process of producing this position statement revealed areas of uncertainty and important gaps in the literature regarding the use of ultrasound guidance for central and peripheral venous access and arterial access.

This position statement recommends a preprocedural ultrasound evaluation of blood vessels based on evidence that providers may detect anatomic anomalies, thrombosis, or vessel stenosis. Ultrasound can also reveal unsuspected high-risk structures in near proximity to the procedure site. Although previous studies have shown that providers can accurately assess vessels with ultrasound for these features, further study is needed to evaluate the effect of a standardized preprocedural ultrasound exam on clinical and procedural decision-making, as well as procedural outcomes.

Second, two ultrasound applications that are being increas- 
ingly used but have not been widely implemented are the use of ultrasound to evaluate lung sliding postprocedure to exclude pneumothorax and the verification of central line placement using a rapid infusion of agitated saline to visualize the RASS. ${ }^{139-141}$ Both of these applications have the potential to expedite postprocedure clearance of central lines for usage and decrease patient radiation exposure by obviating the need for postprocedure CXRs. Despite the supporting evidence, both of these applications are not yet widely used, as few providers have been trained in these techniques which may be considered advanced skills.

Third, despite advances in our knowledge of effective training for vascular access procedures, there is limited agreement on how to define procedural competence. Notable advancements in training include improved understanding of systematic training programs, development of techniques for proctoring procedures, definition of elements for hands-on assessments, and definition of minimum experience needed to perform vascular access procedures independently. However, application of these concepts to move learners toward independent practice remains variably interpreted at different institutions, likely due to limited resources, engrained cultures about procedures, and a lack of national standards. The development of hospitalist-based procedure services at major academic medical centers with high training standards, close monitoring for quality assurance, and the use of databases to track clinical outcomes may advance our understanding and delivery of optimal procedural training.

Finally, ultrasound technology is rapidly evolving which will affect training, techniques, and clinical outcomes in coming years. Development of advanced imaging software with artificial intelligence can improve needle visualization and tracking. These technologies have the potential to facilitate provider training in real-time ultrasound-guided procedures and improve the overall safety of procedures. Emergence of affordable, handheld ultrasound devices is improving access to ultrasound technology, but their role in vascular access procedures is yet to be defined. Furthermore, availability of wireless handheld ultrasound technology and multifrequency transducers will create new possibilities for use of ultrasound in vascular access procedures.

\section{CONCLUSION}

We have presented several evidence-based recommendations on the use of ultrasound guidance for placement of central and peripheral vascular access catheters that are intended for hospitalists and other healthcare providers who routinely perform vascular access procedures. By allowing direct visualization of the needle tip and target vessel, the use of ultrasound guidance has been shown in randomized studies to reduce needle insertion attempts, reduce needle redirections, and increase overall procedure success rates. The accuracy of ultrasound to identify the target vessel, assess for thrombosis, and detect anatomical anomalies is superior to that of physical examination. Hospitalists can attain competence in performing ultrasound-guided vascular access procedures through systematic training programs that combine didactic and hands-on training, which optimally include patient-based competency assessments.

\section{Acknowledgments}

The authors thank all the members of the Society of Hospital Medicine Pointof-care Ultrasound Task Force and the Education Committee members for their time and dedication to develop these guidelines.

Collaborators of Society of Hospital Medicine Point-of-care Ultrasound Task Force: Robert Arntfield, Jeffrey Bates, Anjali Bhagra, Michael Blaivas, Daniel Brotman, Richard Hoppmann, Susan Hunt, Trevor P. Jensen, Venkat Kalidindi, Ketino Kobaidze, Joshua Lenchus, Paul Mayo, Satyen Nichani, Vicki Noble, Nitin Puri, Aliaksei Pustavoitau, Kreegan Reierson, Gerard Salame, Kirk Spencer, Vivek Tayal, David Tierney

SHM Point-of-care Ultrasound Task Force: CHAIRS: Nilam J. Soni, Ricardo Franco-Sadud, Jeff Bates. WORKING GROUPS: Thoracentesis Working Group: Ria Dancel (chair), Daniel Schnobrich, Nitin Puri. Vascular Access Working Group: Ricardo Franco (chair), Benji Mathews, Saaid Abdel-Ghani, Sophia Rodgers, Martin Perez, Daniel Schnobrich. Paracentesis Working Group: Joel Cho (chair), Benji Mathews, Kreegan Reierson, Anjali Bhagra, Trevor P. Jensen Lumbar Puncture Working Group: Nilam J. Soni (chair), Ricardo Franco, Gerard Salame, Josh Lenchus, Venkat Kalidindi, Ketino Kobaidze. Credentialing Working Group: Brian P Lucas (chair), David Tierney, Trevor P. Jensen PEER REVIEWERS Robert Arntfield, Michael Blaivas, Richard Hoppmann, Paul Mayo, Vicki Noble, Aliaksei Pustavoitau, Kirk Spencer, Vivek Tayal. METHODOLOGIST: Mahmoud El-Barbary. LIBRARIAN: Loretta Grikis. SOCIETY OF HOSPITAL MEDICINE EDUCATION COMMITTEE: Daniel Brotman (past chair), Satyen Nichani (current chair), Susan Hunt. SOCIETY OF HOSPITAL MEDICINE STAFF: Nick Marzano.

Disclaimer: The contents of this publication do not represent the views of the U.S. Department of Veterans Affairs or the United States Government.

Disclosure: The authors have nothing to disclose.

Funding: Brian P Lucas: Department of Veterans Affairs, Veterans Health Administration, Office of Research and Development and Dartmouth SYNERGY, National Institutes of Health, National Center for Translational Science (UL1TR001086). Nilam Soni: Department of Veterans Affairs, Quality Enhancement Research Initiative Partnered Evaluation Initiative Grant (HX002263-01A1)

\section{References}

1. Raad I. Intravascular-catheter-related infections. Lancet. 1998;351(9106):893898. https://doi.org/10.1016/S0140-6736(97)10006-X.

2. Merrer J, De Jonghe B, Golliot F, et al. Complications of femoral and subclavian venous catheterization in critically ill patients: a randomized controlled trial. JAMA. 2001;286(6):700-707. https://doi.org/10.1001/jama.286.6.700

3. Sznajder JI, Zveibil FR, Bitterman H, Weiner P, Bursztein S. Central vein catheterization. Failure and complication rates by three percutaneous approaches. Arch Intern Med. 1986;146(2):259-261. https://doi.org/10.1001/ archinte.146.2.259.

4. Randolph AG, Cook DJ, Gonzales CA, Pribble CG. Ultrasound guidance for placement of central venous catheters: a meta-analysis of the literature. Crit Care Med. 1996;24(12):2053-2058. https://doi.org/10.1097/00003246$199612000-00020$

5. Hind D, Calvert N, McWilliams R, et al. Ultrasonic locating devices for central venous cannulation: meta-analysis. BMJ. 2003;327(7411):361. https://doi. org/10.1136/bmj.327.7411.361.

6. O'Grady NP, Alexander M, Burns LA, et al. Guidelines for the prevention of intravascular catheter-related infections. Am J Infect Control. 2011;39(4):S1S34. https://doi.org/10.1016/j.ajic.2011.01.003.

7. National Institute for Health and Care Excellence (NICE). Guidance on the Use of Ultrasound Locating Devices for Placing Central Venous Catheters; 2002

8. Shojania KG, Duncan BW, McDonald KM, et al. Making health care safer: A critical analysis of patient safety practices. Evid Rep Technol Assess. Rockville, MD: Agency for Healthcare Research and Quality. 2001;43(43):i-x, 1. 
9. Lamperti M, Bodenham AR, Pittiruti M, et al. International evidence-based recommendations on ultrasound-guided vascular access. Intensive Care Med. 2012;38(7):1105-1117. https://doi.org/10.1007/s00134-012-2597-x.

10. Frykholm P, Pikwer A, Hammarskjöld F, et al. Clinical guidelines on central venous catheterisation. Swedish Society of Anaesthesiology and Intensive Care Medicine. Acta Anaesthesiol Scand. 2014;58(5):508-524. https://doi org/10.1111/aas.12295.

11. American Society of Anesthesiologists Task Force on Central Venous Access, Rupp SM, Apfelbaum JL, et al. Practice guidelines for central venous access: a report by the American Society of Anesthesiologists Task Force on Central Venous Access. Anesthesiology. 2012;116(3):539-573. https://doi. org/10.1097/ALN.0b013e31823c9569.

12. Frankel HL, Kirkpatrick AW, Elbarbary M, et al. Guidelines for the appropriate use of bedside general and cardiac ultrasonography in the evaluation of critically ill patients-part I: General ultrasonography. Crit Care Med. 2015:43(11):2479-2502. https://doi.org/10.1097/CCM.0000000000001216.

13. Shekelle PG, Wachter RM, Pronovost PJ, et al. Making health care safer II: An updated critical analysis of the evidence for patient safety practices. Evid Rep Technol Assess. 2013;211:1-945.

14. Troianos CA, Hartman GS, Glas KE, et al. Guidelines for performing ultrasound guided vascular cannulation: recommendations of the American Society of Echocardiography and the Society of Cardiovascular Anesthesiologists. J Am Soc Echocardiogr. 2011;24(12):1291-1318. https://doi. org/10.1016/j.echo.2011.09.021

15. Soni NJ, Reyes LF, Keyt H, et al. Use of ultrasound guidance for central venous catheterization: a national survey of intensivists and hospitalists. J Crit Care. 2016;36:277-283. https://doi.org/10.1016/j.jcrc.2016.07.014.

16. Parienti JJ, Mongardon N, Mégarbane B, et al. Intravascular complications of central venous catheterization by insertion site. $N$ Engl J Med. 2015;373(13):1220-1229. https://doi.org/10.1056/NEJMoa1500964.

17. Maizel J, Bastide MA, Richecoeur J, et al. Practice of ultrasound-guided central venous catheter technique by the French intensivists: a survey from the BoReal study group. Ann Intensive Care. 2016;6(1):76. https://doi org/10.1186/s13613-016-0177-x.

18. Egan $G$, Healy $D, O^{\prime} N e i l l ~ H$, et al. Ultrasound guidance for difficult peripheral venous access: systematic review and meta-analysis. Emerg Med J. 2013;30(7):521-526. https://doi.org/10.1136/emermed-2012-201652.

19. Stolz LA, Stolz U, Howe C, Farrell IJ, Adhikari S. Ultrasound-guided peripheral venous access: a meta-analysis and systematic review. J Vasc Access. 2015;16(4):321-326. https://doi.org/10.5301/jva.5000346.

20. Sofocleous CT, Schur I, Cooper SG, et al. Sonographically guided placement of peripherally inserted central venous catheters: review of 355 procedures. AJR Am J Roentgenol. 1998;170(6):1613-1616. https://doi.org/10.2214/ ajr.170.6.9609183.

21. Nichols I, Humphrey JP. The efficacy of upper arm placement of peripherally inserted central catheters using bedside ultrasound and microintroducer technique. J Infus Nurs Off Publ Infus Nurs Soc. 2008;31(3):165-176. https:// doi.org/10.1097/01.NAN.0000317703.66395.b8.

22. Stokowski G, Steele D, Wilson D. The use of ultrasound to improve practice and reduce complication rates in peripherally inserted central catheter insertions. J Infus Nurs Off Pub/ Infus Nurs Soc. 2009;32(3):145-155. https:// doi.org/10.1097/NAN.0b013e3181a1a98f.

23. Shiloh AL, Savel RH, Paulin LM, Eisen LA. Ultrasound-guided catheterization of the radial artery: a systematic review and meta-analysis of randomized controlled trials. Chest. 2011;139(3):524-529. https://doi.org/10.1378/ chest.10-0919.

24. Lucas BP, Tierney DM, Jensen TP, et al. Credentialing of hospitalists in ultrasound-guided bedside procedures: A position statement of the Society of Hospital Medicine. J Hosp Med. 2018;13(2):117-125. https://doi. org/10.12788/jhm.2917.

25. Chopra V, Flanders SA, Saint S, et al. The Michigan appropriateness guide for intravenous catheters (Magic): results From a Multispecialty Panel Using the RAND/UCLA Appropriateness Method. Ann Intern Med. 2015;163(6):S1 S40. https://doi.org/10.7326/M15-0744.

26. Raad II, Hohn DC, Gilbreath BJ, et al. Prevention of central venous catheter-related infections by using maximal sterile barrier precautions during insertion. Infect Control Hosp Epidemiol. 1994;15(4):231-238.

27. Slama M, Novara A, Safavian A, et al. Improvement of internal jugular vein cannulation using an ultrasound-guided technique. Intensive Care Med. 1997;23(8):916-919. https://doi.org/10.1007/s001340050432

28. Seyahi N, Kahveci A, Altiparmak MR, Serdengecti K, Erek E. Ultrasound imaging findings of femoral veins in patients with renal failure and its impact on vascular access. Nephrol Dial Transplant. 2005;20(9):1864-1867. https:// doi.org/10.1093/ndt/gfh942.
29. Lin BS, Kong CW, Tarng DC, Huang TP, Tang GJ. Anatomical variation of the internal jugular vein and its impact on temporary haemodialysis vascular access: an ultrasonographic survey in uraemic patients. Nephrol Dial Transplant. 1998;13(1):134-138. https://doi.org/10.1093/ndt/13.1.134.

30. Troianos CA, Kuwik RJ, Pasqual JR, Lim AJ, Odasso DP. Internal jugular vein and carotid artery anatomic relation as determined by ultrasonography. Anesthesiology. 1996;85(1):43-48. https://doi.org/10.1097/00000542199607000-00007.

31. Gordon AC, Wright I, Pugh ND. Duplication of the superficial femoral vein: recognition with duplex ultrasonography. Clin Rad. 1996;51(9):622-624. https://doi.org/10.1016/S0009-9260(96)80055-9

32. Sulek CA, Gravenstein N, Blackshear RH, Weiss L. Head rotation during internal jugular vein cannulation and the risk of carotid artery puncture. Anesth Analg. 1996;82(1):125-128. https://doi.org/10.1097/00000539-19960100000022.

33. Shrestha BR, Gautam B. Ultrasound versus the landmark technique: a prospective randomized comparative study of internal jugular vein cannulation in an intensive care unit. JNMA J Nepal Med Assoc. 2011;51(182):56-61. https://doi.org/10.31729/jnma.148.

34. Brederlau J, Greim C, Schwemmer U, et al. Ultrasound-guided cannulation of the internal jugular vein in critically ill patients positioned in 30 degrees dorsal elevation. Eur J Anaesthesiol. 2004;21(9):684-687. https://doi. org/10.1097/00003643-200409000-00003.

35. Lamperti $M$, Subert $M$, Cortellazzi $P$, et al. Is a neutral head position safer than 45-degree neck rotation during ultrasound-guided internal jugular vein cannulation? Results of a randomized controlled clinical trial. Anesth Analg. 2012;114(4):777-784. https://doi.org/10.1213/ANE.0b013e3182459917.

36. Benter T, Teichgräber UK, Klühs $L$, et al. Anatomical variations in the internal jugular veins of cancer patients affecting central venous access. Anatomical variation of the internal jugular vein. Ultraschall Med. 2001;22(1):23-26. https://doi.org/10.1055/s-2001-11243

37. Caridi JG, Hawkins IF, Jr, Wiechmann BN, Pevarski DJ, Tonkin JC. Sonographic guidance when using the right internal jugular vein for central vein access. AJR Am J Roentgenol. 1998;171(5):1259-1263. https://doi. org/10.2214/ajr.171.5.9798857

38. Brusasco C, Corradi F, Zattoni PL, et al. Ultrasound-guided central venous cannulation in bariatric patients. Obes Surg. 2009;19(10):1365-1370. https:// doi.org/10.1007/s11695-009-9902-y.

39. Armstrong PJ, Cullen M, Scott DH. The 'SiteRite' ultrasound machine--an aid to internal jugular vein cannulation. Anaesthesia. 1993;48(4):319-323. https://doi.org/10.1111/j.1365-2044.1993.tb06953.x.

40. Forauer AR, Glockner JF. Importance of US findings in access planning during jugular vein hemodialysis catheter placements. J Vasc Interv Rad. 2000;11(2 Pt 1):233-238. https://doi.org/10.1016/S1051-0443(07)61471-7.

41. Hassan C, Girishkumar HT, Thatigotla B, et al. Value of ultrasound guidance in placement of hemodialysis access catheters in patients with end-stage renal disease. Am Surg. 2008;74(11):1111-1113.

42. Tan CO, Weinberg L, Peyton P, Story D, McNicol L. Size variation between contralateral infraclavicular axillary veins within individual patients-implications for subclavian venous central line insertion. Crit Care Med. 2013;41(2):457-463. https://doi.org/10.1097/CCM.0b013e31826ab1dd.

43. Wu SY, Ling $Q$, Cao LH, et al. Real-time two-dimensional ultrasound guidance for central venous cannulation: a meta-analysis. Anesthesiology. 2013;118(2):361-375. https://doi.org/10.1097/ALN.0b013e31827bd172.

44. Kim W, Chung RK, Lee GY, Han JI. The effects of hip abduction with external rotation and reverse Trendelenburg position on the size of the femoral vein; ultrasonographic investigation. Korean J Anesthesiol. 2011;61(3):205-209. https://doi.org/10.4097/kjae.2011.61.3.205.

45. Denys BG, Uretsky BF. Anatomical variations of internal jugular vein location: impact on central venous access. Crit Care Med. 1991;19(12):1516-1519. https://doi.org/10.1097/00003246-199112000-00013.

46. Brass P, Hellmich M, Kolodziej L, Schick G, Smith AF. Ultrasound guidance versus anatomical landmarks for internal jugular vein catheterization. Cochrane Database Syst Rev. 2015;1:CD006962. https://doi.org/10.1002/14651858. CD006962.pub2.

47. Gilbert TB, Seneff MG, Becker RB. Facilitation of internal jugular venous cannulation using an audio-guided Doppler ultrasound vascular access device: results from a prospective, dual-center, randomized, crossover clinical study. Crit Care Med. 1995;23(1):60-65. https://doi.org/10.1097/00003246199501000-00012.

48. Schummer W, Schummer $C$, Tuppatsch $H$, et al. Ultrasound-guided central venous cannulation: is there a difference between Doppler and B-mode ultrasound? J Clin Anesth. 2006;18(3):167-172. https://doi.org/10.1016/j. jclinane.2005.12.010. 
49. Airapetian N, Maizel J, Langelle F, et al. Ultrasound-guided central venous cannulation is superior to quick-look ultrasound and landmark methods among inexperienced operators: a prospective randomized study. Inten sive Care Med. 2013;39(11):1938-1944. https://doi.org/10.1007/s00134-0133072-z.

50. Milling TJ, Jr, Rose J, Briggs WM, et al. Randomized, controlled clinical trial of point-of-care limited ultrasonography assistance of central venous cannulation: the Third Sonography Outcomes Assessment Program (SOAP 3) Trial. Crit Care Med. 2005;33(8):1764-1769. https://doi.org/10.1097/01. ccm.0000171533.92856.e5

51. Beaudoin FL, Merchant RC, Lincoln J, et al. Bedside ultrasonography detects significant femoral vessel overlap: implications for central venous cannulation. CJEM. 2011;13(4):245-250. https://doi.org/10.2310/8000.2011.110482.

52. Kwon TH, Kim YL, Cho DK. Ultrasound-guided cannulation of the femoral vein for acute haemodialysis access. Nephrol Dial Transplant 1997;12(5):1009-1012. https://doi.org/10.1093/ndt/12.5.1009.

53. Rothschild JM. Ultrasound guidance of central vein catheterization. Evid Rep Technol Assess. 2001;43. Chapter 21.:http://archive.ahrq.gov/clinic/ ptsafety/chap21.htm.

54. Lennon M, Zaw NN, Pöpping DM, Wenk M. Procedural complications of central venous catheter insertion. Minerva Anestesiol. 2012;78(11):1234-1240.

55. Blaivas M, Adhikari S. An unseen danger: frequency of posterior vessel wall penetration by needles during attempts to place internal jugular vein central catheters using ultrasound guidance. Crit Care Med. 2009;37(8):23452349; quiz 2359. https://doi.org/10.1097/CCM.0b013e3181a067d4

56. Vogel JA, Haukoos JS, Erickson CL, et al. Is long-axis view superior to short-axis view in ultrasound-guided central venous catheterization? Crit Care Med 2015;43(4):832-839. https://doi.org/10.1097/CCM.0000000000000823.

57. Tammam TF, El-Shafey EM, Tammam HF. Ultrasound-guided internal jugular vein access: comparison between short axis and long axis techniques. Saudi J Kidney Dis Transpl. 2013;24(4):707-713. https://doi.org/10.4103/13192442.113861.

58. Keyes LE, Frazee BW, Snoey ER, Simon BC, Christy D. Ultrasound-guided brachial and basilic vein cannulation in emergency department patients with difficult intravenous access. Ann Emerg Med. 1999;34(6):711-714. https:// doi.org/10.1016/S0196-0644(99)70095-8.

59. Mahler SA, Wang $\mathrm{H}$, Lester $\mathrm{C}$, et al. Short- vs long-axis approach to ultrasound-guided peripheral intravenous access: a prospective randomized study. Am J Emerg Med. 2011;29(9):1194-1197. https://doi.org/10.1016/j. ajem.2010.07.015

60. Berk D, Gurkan Y, Kus A, et al. Ultrasound-guided radial arterial cannulation: long axis/in-plane versus short axis/out-of-plane approaches? J Clin Monit Comput. 2013;27(3):319-324. https://doi.org/10.1007/s10877-013-9437-6.

61. Batllori M, Urra M, Uriarte $E$, et al. Randomized comparison of three transducer orientation approaches for ultrasound guided internal jugular venous cannulation. Br J Anaesth. 2016;116(3):370-376. https://doi.org/10.1093/bja/ aev399.

62. Moak JH, Lyons MS, Wright SW, Lindsell CJ. Needle and guidewire visualization in ultrasound-guided internal jugular vein cannulation. Am J Emerg Med. 2011;29(4):432-436. https://doi.org/10.1016/j.ajem.2010.01.004.

63. Moak JH, Rajkumar JS, Woods WA. The wire is really easy to see (WIRES): sonographic visualization of the guidewire by novices. CJEM. 2013;15(1):1823. https://doi.org/10.2310/8000.2012.120800.

64. Gillman LM, Blaivas M, Lord J, Al-Kadi A, Kirkpatrick AW. Ultrasound confirmation of guidewire position may eliminate accidental arterial dilatation during central venous cannulation. Scand J Trauma Resusc Emerg Med. 2010;18:39. https://doi.org/10.1186/1757-7241-18-39.

65. Augoustides JG, Horak J, Ochroch AE, et al. A randomized controlled clinical trial of real-time needle-guided ultrasound for internal jugular venous cannulation in a large university anesthesia department. J Cardiothorac Vasc Anesth. 2005;19(3):310-315. https://doi.org/10.1053/j.jvca.2005.03.007.

66. Maecken T, Heite L, Wolf B, Zahn PK, Litz RJ. Ultrasound-guided catheterisation of the subclavian vein: freehand vs needle-guided technique. Anaesthesia. 2015;70(11):1242-1249. https://doi.org/10.1111/anae.13187.

67. Stone MB, Nagdev A, Murphy MC, Sisson CA. Ultrasound detection of guidewire position during central venous catheterization. Am J Emerg Med. 2010;28(1):82-84. https://doi.org/10.1016/j.ajem.2008.09.019

68. Luyet $C$, Hartwich V, Urwyler $N$, et al. Evaluation of a novel needle guide for ultrasound-guided phantom vessel cannulation. Anaesthesia. 2011;66(8):715-720. https://doi.org/10.1111/j.1365-2044.2011.06781.x.

69. O'Grady NP, Alexander M, Burns LA, et al. Summary of recommendations: Guidelines for the Prevention of Intravascular Catheter-related Infections. Clin Infect Dis. 2011;52(9):1087-1099. https://doi.org/10.1093/cid/cir138.

70. Southworth SL, Henman LJ, Kinder LA, Sell JL. The journey to zero central catheter-associated bloodstream infections: culture change in an intensive care unit. Crit Care Nurse. 2012;32(2):49-54. https://doi.org/10.4037/ ccn2012915.

71. Guerin K, Wagner J, Rains K, Bessesen M. Reduction in central line-associated bloodstream infections by implementation of a postinsertion care bundle. Am J Infect Control. 2010;38(6):430-433. https://doi.org/10.1016/j. ajic.2010.03.007.

72. Hartman N, Wittler M, Askew K, Manthey D. Delphi method validation of a procedural performance checklist for insertion of an ultrasound-guided internal jugular central line. Am J Med Qual Off J Am Coll Med Qual. 2016;31(1):81-85. https://doi.org/10.1177/1062860614549762.

73. Lenchus JD, Carvalho CM, Ferreri K, et al. Filling the void: defining invasive bedside procedural competency for internal medicine residents. J Grad Med Educ. 2013;5(4):605-612. https://doi.org/10.4300/JGME-D-13-00030.1.

74. Barsuk JH, Cohen ER, Feinglass J, McGaghie WC, Wayne DB. Use of simulation-based education to reduce catheter-related bloodstream infections. Arch Intern Med. 2009;169(15):1420-1423. https://doi.org/10.1001/archinternmed.2009.215.

75. Karakitsos D, Labropoulos N, De Groot E, et al. Real-time ultrasound-guided catheterisation of the internal jugular vein: a prospective comparison with the landmark technique in critical care patients. Crit Care. 2006;10(6):R162. https://doi.org/10.1186/cc5101

76. Berenholtz SM, Pronovost PJ, Lipsett PA, et al. Eliminating catheter-related bloodstream infections in the intensive care unit. Crit Care Med. 2004;32(10):2014-2020. https://doi.org/10.1097/01.ccm.0000142399.70913.2f.

77. Young EM, Commiskey ML, Wilson SJ. Translating evidence into practice to prevent central venous catheter-associated bloodstream infections: a systems-based intervention. Am J Infect Control. 2006;34(8):503-506. https:// doi.org/10.1016/j.ajic.2006.03.011

78. Galpern D, Guerrero A, Tu A, Fahoum B, Wise L. Effectiveness of a central line bundle campaign on line-associated infections in the intensive care unit. Surgery. 2008;144(4):492-495; discussion 495. https://doi.org/10.1016/j. surg.2008.06.004.

79. Mermel LA, McCormick RD, Springman SR, Maki DG. The pathogenesis and epidemiology of catheter-related infection with pulmonary artery swan-Ganz catheters: a prospective study utilizing molecular subtyping. Am J Med. 1991;91(3b):197S-205S. https://doi.org/10.1016/0002-9343(91)90369-9.

80. Marschall J, Mermel LA, Classen D, et al. Strategies to prevent central line-associated bloodstream infections in acute care hospitals. Infect Control Hosp Epidemiol. 2008;29(1):S22-S30. https://doi.org/10.1086/591059.

81. Marschall J, Mermel LA, Fakih M, et al. Strategies to prevent central line-associated bloodstream infections in acute care hospitals: 2014 update. Infect Control Hosp Epidemiol. 2014;35(7):753-771. https://doi. org/10.1086/676533.

82. Garcia-Rodriguez JF, Álvarez-Díaz H, Vilariño-Maneiro L, et al. Epidemiology and impact of a multifaceted approach in controlling central venous catheter associated blood stream infections outside the intensive care unit. BMC Infect Dis. 2013;13:445. https://doi.org/10.1186/1471-2334-13-445.

83. Lee DH, Jung KY, Choi YH. Use of maximal sterile barrier precautions and/ or antimicrobial-coated catheters to reduce the risk of central venous catheter-related bloodstream infection. Infect Control Hosp Epidemiol. 2008;29(10):947-950. https://doi.org/10.1086/590356.

84. Mermel LA. Prevention of intravascular catheter-related infections. Ann Intern Med. 2000;132(5):391-402. https://doi.org/10.7326/0003-4819-132-5200003070-00009

85. Troianos CA, Jobes DR, Ellison N. Ultrasound-guided cannulation of the internal jugular vein. A prospective, randomized study. Anesth Analg. 1991;72(6):823-826. https://doi.org/10.1213/00000539-199106000-00020.

86. Troianos CA, Savino JS. Internal jugular vein cannulation guided by echocardiography. Anesthesiology. 1991;74(4):787-789. https://doi. org/10.1097/00000542-199104000-00026.

87. Denys BG, Uretsky BF, Reddy PS, et al. An ultrasound method for safe and rapid central venous access. N Engl J Med. 1991;324(8):566. https://doi. org/10.1056/NEJM199102213240816.

88. Riaz A, Shan Khan RA, Salim F. Ultrasound guided internal jugular venous cannulation: comparison with land-mark technique. J Coll Phys Surg Pak. 2015;25(5):315-319. https://doi.org/05.2015/JCPSP.315319.

89. Gok F, Kilicaslan A, Sarkilar G, Kandemir B, Yosunkaya A. The effect of ultrasound guidance on central venous catheter-associated bloodstream infection in critical care patients. Acta Med Mediterr. 2013;29:677-682.

90. Lamperti M, Cortellazzi P, D'Onofrio G, et al. An outcome study on complications using routine ultrasound assistance for internal jugular vein cannulation. Acta Anaesthesiol Scand. 2007;51(10):1327-1330. https://doi. org/10.1111/j.1399-6576.2007.01442.x. 
91. Vezzani A, Manca T, Vercelli A, Braghieri A, Magnacavallo A. Ultrasonography as a guide during vascular access procedures and in the diagnosis of complications. J Ultrasound. 2013;16(4):161-170. https://doi.org/10.1007/ s40477-013-0046-5.

92. Palepu GB, Deven J, Subrahmanyam M, Mohan S. Impact of ultrasonography on central venous catheter insertion in intensive care. Indian J Rad Imaging. 2009;19(3):191-198. https://doi.org/10.4103/0971-3026.54877.

93. Agarwal A, Singh DK, Singh AP. Ultrasonography: a novel approach to central venous cannulation. Indian J Crit Care Med. 2009;13(4):213-216. https:// doi.org/10.4103/0972-5229.60174

94. Wong SW, Niazi AU, Chin KJ, Chan WW. Real-time ultrasound-guided spinal anesthesia using the SonixGPS ${ }^{\circledR}$ needle tracking system: a case report. Can J Anaesth. 2013;60(1):50-53. https://doi.org/10.1007/s12630-012-9809-2.

95. Bouaziz H, Zetlaoui PJ, Pierre S, et al. Guidelines on the use of ultrasound guidance for vascular access. Anaesth, Crit Care Pain Med. 2015;34(1):65-69. https://doi.org/10.1016/j.accpm.2015.01.004.

96. Jenssen C, Brkljacic B, Hocke M, et al. EFSUMB guidelines on interventional ultrasound (INVUS), Part VI - Ultrasound-guided vascular interventions. UI traschall Med. 2016;37(5):473-476. https://doi.org/10.1055/s-0035-1553450.

97. Rando K, Castelli J, Pratt JP, et al. Ultrasound-guided internal jugular vein catheterization: a randomized controlled trial. Heart Lung Vessels. 2014;6(1):13-23.

98. Mey U, Glasmacher A, Hahn C, et al. Evaluation of an ultrasound-guided technique for central venous access via the internal jugular vein in $493 \mathrm{pa}$ tients. Support Care Cancer Off J Multinat Assoc Support Care Cancer. 2003;11(3):148-155. https://doi.org/10.1007/s00520-002-0399-3.

99. Singh SA, Sharma S, Singh A, et al. The safety of ultrasound guided central venous cannulation in patients with liver disease. Saudi J Anaesth 2015;9(2):155-160. https://doi.org/10.4103/1658-354X.152842.

100. Akoglu H, Piskinpasa S, Yenigun EC, et al. Real-time ultrasound guided placement of temporary internal jugular vein catheters: assessment of technical success and complication rates in nephrology practice. Nephrol (Carlton). 2012;17(7):603-606. https://doi.org/10.1111/j.1440 1797.2012.01637.x.

101. Sadler DJ, Gordon AC, Klassen J, et al. Image-guided central venous catheters for apheresis. Bone Marrow Transplant. 1999;23(2):179-182. https://doi. org/10.1038/sj.bmt.1701545.

102. Calvert N, Hind D, McWilliams R, et al. Ultrasound for central venous cannulation: economic evaluation of cost-effectiveness. Anaesthesia. 2004;59(11):1116-1120. https://doi.org/10.1111/j.1365-2044.2004.03906.x.

103. Goetz AM, Wagener MM, Miller JM, Muder RR. Risk of infection due to central venous catheters: effect of site of placement and catheter type. Infect Control Hosp Epidemiol. 1998;19(11):842-845.

104. Bertini P, Frediani M. Ultrasound guided supraclavicular central vein cannulation in adults: a technical report. J Vasc Access. 2013;14(1):89-93. https:// doi.org/10.5301/jva.5000088

105. Lalu MM, Fayad A, Ahmed O, et al. Ultrasound-guided subclavian vein catheterization: A systematic review and meta-analysis. Crit Care Med. 2015;43(7):1498-1507. https://doi.org/10.1097/CCM.0000000000000973.

106. Milone M, Di Minno G, Di Minno MN, et al. The real effectiveness of ultrasound guidance in subclavian venous access. Ann ital chir. 2010;81(5):331-334

107. O'Leary R, Ahmed SM, McLure H, et al. Ultrasound-guided infraclavicular axillary vein cannulation: a useful alternative to the internal jugular vein. $\mathrm{Br} \mathrm{J}$ Anaesth. 2012;109(5):762-768. https://doi.org/10.1093/bja/aes262.

108. Gualtieri E, Deppe SA, Sipperly ME, Thompson DR. Subclavian venous catheterization: greater success rate for less experienced operators using ultrasound guidance. Crit Care Med. 1995;23(4):692-697. https://doi. org/10.1097/00003246-199504000-00018.

109. Fragou M, Gravvanis A, Dimitriou V, et al. Real-time ultrasound-guided subclavian vein cannulation versus the landmark method in critical care patients: a prospective randomized study. Crit Care Med. 2011;39(7):1607-1612. https://doi.org/10.1097/CCM.0b013e318218a1ae.

110. Brass P, Hellmich M, Kolodziej L, Schick G, Smith AF. Ultrasound guidance versus anatomical landmarks for subclavian or femoral vein catheterization. Cochrane Database Syst Rev. 2015;1:CD011447. https://doi. org/10.1002/14651858.CD011447.

111. Robinson MK, Mogensen KM, Grudinskas GF, Kohler S, Jacobs DO. Improved care and reduced costs for patients requiring peripherally inserted central catheters: the role of bedside ultrasound and a dedicated team. JPEN J Parenter Enter Nutr. 2005;29(5):374-379. https://doi.org/10.1177/014 8607105029005374.

112. Li J, Fan $Y Y, X$ in $M Z$, et al. A randomised, controlled trial comparing the long-term effects of peripherally inserted central catheter placement in chemotherapy patients using B-mode ultrasound with modified Seldinger tech- nique versus blind puncture. Eur J Oncol Nurs. 2014;18(1):94-103. https:// doi.org/10.1016/j.ejon.2013.08.003

113. Schweickert WD, Herlitz J, Pohlman AS, et al. A randomized, controlled trial evaluating postinsertion neck ultrasound in peripherally inserted central catheter procedures. Crit Care Med. 2009;37(4):1217-1221. https://doi. org/10.1097/CCM.0b013e31819cee7f.

114. Mahler SA, Wang H, Lester C, Conrad SA. Ultrasound-guided peripheral intravenous access in the emergency department using a modified Seldinger technique. J Emerg Med. 2010;39(3):325-329. https://doi.org/10.1016/j. jemermed.2009.02.013.

115. Brannam L, Blaivas M, Lyon M, Flake M. Emergency nurses' utilization of ultrasound guidance for placement of peripheral intravenous lines in difficult-access patients. Acad Emerg Med. 2004;11(12):1361-1363. https://doi. org/10.1197/j.aem.2004.08.027.

116. Au A, Rotte M, Gryzbowski R, Ku B, Fields J. 157 Decrease in central venous catheter placement and complications due to utilization of ultrasound-guided peripheral intravenous catheters. Ann Emerg Med. 2011;58(4):S230. https://doi.org/10.1016/j.annemergmed.2011.06.185.

117. Dargin JM, Rebholz CM, Lowenstein RA, Mitchell PM, Feldman JA. UItrasonography-guided peripheral intravenous catheter survival in ED patients with difficult access. Am J Emerg Med. 2010;28(1):1-7. https://doi. org/10.1016/j.ajem.2008.09.001

118. Bauman M, Braude D, Crandall C. Ultrasound-guidance vs standard technique in difficult vascular access patients by ED technicians. Am J Emerg Med. 2009;27(2):135-140. https://doi.org/10.1016/j.ajem.2008.02.005.

119. Schoenfeld E, Shokoohi H, Boniface K. Ultrasound-guided peripheral intravenous access in the emergency department: patient-centered survey. West J Emerg Med. 2011;12(4):475-477. https://doi.org/10.5811/westjem.2011.3.1920.

120. Maki DG, Ringer M. Risk factors for infusion-related phlebitis with small peripheral venous catheters. A randomized controlled trial. Ann Intern Med. 1991;114(10):845-854. https://doi.org/10.7326/0003-4819-114-10-845

121. Miliani K, Taravella $R$, Thillard D, et al. Peripheral venous catheter-related adverse events: evaluation from a multicentre epidemiological study in France (the CATHEVAL Project). PLOS ONE. 2017;12(1):e0168637. https:// doi.org/10.1371/journal.pone.0168637.

122. Gregg SC, Murthi SB, Sisley AC, Stein DM, Scalea TM. Ultrasound-guided peripheral intravenous access in the intensive care unit. J Crit Care. 2010;25(3):514-519. https://doi.org/10.1016/j.jcrc.2009.09.003.

123. Adhikari S, Blaivas M, Morrison D, Lander L. Comparison of infection rates among ultrasound-guided versus traditionally placed peripheral intravenous lines. J Ultrasound Med. 2010;29(5):741-747. https://doi.org/10.7863/ jum.2010.29.5.741.

124. Shiver S, Blaivas M, Lyon M. A prospective comparison of ultrasound-guided and blindly placed radial arterial catheters. Acad Emerg Med. 2006;13(12):1275-1279. https://doi.org/10.1197/j.aem.2006.07.015.

125. Levin PD, Sheinin O, Gozal Y. Use of ultrasound guidance in the insertion of radial artery catheters. Crit Care Med. 2003;31(2):481-484. https://doi. org/10.1097/01.CCM.0000050452.17304.2F.

126. Gu WJ, Tie HT, Liu JC, Zeng XT. Efficacy of ultrasound-guided radial artery catheterization: a systematic review and meta-analysis of randomized controlled trials. Crit Care. 2014;18(3):R93. https://doi.org/10.1186/cc13862.

127. Tang L, Wang F, Li Y, et al. Ultrasound guidance for radial artery catheterization: an updated meta-analysis of randomized controlled trials. PLOS ONE. 2014;9(11):e111527. https://doi.org/10.1371/journal.pone.0111527.

128. Sobolev M, Slovut DP, Lee Chang A, Shiloh AL, Eisen LA. Ultrasound-guided catheterization of the femoral artery: A systematic review and meta-analysis of randomized controlled trials. J Invas Cardiol. 2015;27(7):318-323. https:// doi.org/10.1378/chest.1991181.

129. Gabriel M, Pawlaczyk K, Waliszewski K, Krasiński Z, Majewski W. Location of femoral artery puncture site and the risk of postcatheterization pseudoaneurysm formation. Int J Cardiol. 2007;120(2):167-171. https://doi.org/10.1016/j. ijcard.2006.09.018.

130. Seto AH, Abu-Fadel MS, Sparling JM, et al. Real-time ultrasound guidance facilitates femoral arterial access and reduces vascular complications: FAUST (Femoral Arterial Access With ultrasound Trial). JACC CardiovasC Interv. 2010;3(7):751-758. https://doi.org/10.1016/j.jcin.2010.04.015.

131. Kalish J, Eslami M, Gillespie D, et al. Routine use of ultrasound guidance in femoral arterial access for peripheral vascular intervention decreases groin hematoma rates. J Vasc Surg. 2015;61(5):1231-1238. https://doi. org/10.1016/j.jvs2014.12.003.

132. Sandhu NS, Patel B. Use of ultrasonography as a rescue technique for failed radial artery cannulation. J Clin Anesth. 2006;18(2):138-141. https://doi. org/10.1016/j.jclinane.2005.06.011. 
133. White L, Halpin A, Turner M, Wallace L. Ultrasound-guided radial artery cannulation in adult and paediatric populations: a systematic review and meta-analysis. Br J Anaesth. 2016;116(5):610-617. https://doi.org/10.1093/ bja/aew097.

134. Gao YB, Yan JH, Gao FQ, et al. Effects of ultrasound-guided radial artery catheterization: an updated meta-analysis. Am J Emerg Med. 2015;33(1):5055. https://doi.org/10.1016/j.ajem.2014.10.008.

135. Seto AH, Roberts JS, Abu-Fadel MS, et al. Real-time ultrasound guidance facilitates transradial access: RAUST (Radial Artery Access with Ultrasound Trial). JACC Cardiovasc Interv. 2015;8(2):283-291. https://doi.org/10.1016/j. jcin.2014.05.036

136. Roberts J, Manur R. Ultrasound-guided radial artery access by a non-ultrasound trained interventional cardiologist improved first-attempt success rates and shortened time for successful radial artery cannulation. J Invas Cardiol. 2013;25(12):676-679

137. Lichtenstein DA, Menu Y. A bedside ultrasound sign ruling out pneumothorax in the critically ill. Lung sliding. Chest. 1995;108(5):1345-1348. https://doi. org/10.1378/chest.108.5.1345

138. Lichtenstein D, Mezière G, Biderman P, Gepner A. The comet-tail artifact: an ultrasound sign ruling out pneumothorax. Intensive Care Med. 1999;25(4):383-388. https://doi.org/10.1007/s001340050862.

139. Ablordeppey EA, Drewry AM, Beyer AB, et al. Diagnostic accuracy of central venous catheter confirmation by bedside ultrasound Versus chest radiography in critically ill patients: A systematic review and meta-analysis. Crit Care Med. 2017;45(4):715-724. https://doi.org/10.1097/CCM.0000000000002188.

140. Bedel J, Vallée F, Mari A, et al. Guidewire localization by transthoracic echocardiography during central venous catheter insertion: a periprocedural method to evaluate catheter placement. Intensive Care Med. 2013;39(11):1932-1937. https://doi.org/10.1007/s00134-013-3097-3.

141. Weekes AJ, Keller SM, Efune B, Ghali S, Runyon M. Prospective comparison of ultrasound and CXR for confirmation of central vascular catheter placement. Emerg Med J EMJ. 2016;33(3):176-180. https://doi.org/10.1136/ emermed-2015-205000.

142. Arellano R, Nurmohamed A, Rumman A, et al. The utility of transthoracic echocardiography to confirm central line placement: an observational study. Can J Anaesth. 2014;61(4):340-346. https://doi.org/10.1007/s12630-014 0111-3.

143. Vezzani A, Brusasco C, Palermo S, et al. Ultrasound localization of central vein catheter and detection of postprocedural pneumothorax: an alternative to chest radiography. Crit Care Med. 2010;38(2):533-538. https://doi. org/10.1097/CCM.0b013e3181c0328f.

144. Choudhry NK, Fletcher RH, Soumerai SB. Systematic review: the relationship between clinical experience and quality of health care. Ann Intern Med 2005;142(4):260-273. https://doi.org/10.7326/0003-4819-142-4-200502150 00008

145. Backlund BH, Hopkins E, Kendall JL. Ultrasound guidance for central venous access by emergency physicians in Colorado. West J Emerg Med. 2012;13(4):320-325. https://doi.org/10.5811/westjem.2011.11.6821.

146. Buchanan MS, Backlund B, Liao MM, et al. Use of ultrasound guidance for central venous catheter placement: survey from the American Board of Emergency Medicine Longitudinal Study of Emergency Physicians. Acad Emerg Med. 2014;21(4):416-421. https://doi.org/10.1111/acem.12350

147. Barsuk JH, McGaghie WC, Cohen ER, O'Leary KJ, Wayne DB. Simulation-based mastery learning reduces complications during central venous catheter insertion in a medical intensive care unit. Crit Care Med. 2009;37(10):2697-2701. https://doi.org/10.1097/00003246-200910000-00003.

148. Coopersmith CM, Rebmann TL, Zack JE, et al. Effect of an education program on decreasing catheter-related bloodstream infections in the surgical intensive care unit. Crit Care Med. 2002;30(1):59-64. https://doi. org/10.1097/00003246-200201000-00009

149. Woo MY, Frank J, Lee AC, et al. Effectiveness of a novel training program for emergency medicine residents in ultrasound-guided insertion of central venous catheters. CJEM. 2009;11(4):343-348. https://doi.org/10.1017/ S1481803500011398

150. McGee DC, Gould MK. Preventing complications of central venous catheterization. N Engl J Med. 2003;348(12):1123-1133. https://doi.org/10.1056/ NEJMra011883

151. Barsuk JH, McGaghie WC, Cohen ER, Balachandran JS, Wayne DB. Use of simulation-based mastery learning to improve the quality of central venous catheter placement in a medical intensive care unit. J Hosp Med. 2009;4(7):397-403. https://doi.org/10.1002/jhm.468.

152. Sekiguchi $H$, Tokita JE, Minami T, et al. A prerotational, simulation-based workshop improves the safety of central venous catheter insertion: results of a successful internal medicine house staff training program. Chest.
2011;140(3):652-658. https://doi.org/10.1378/chest.10-3319.

153. Feller-Kopman D. Ultrasound-guided internal jugular access: a proposed standardized approach and implications for training and practice. Chest. 2007;132(1):302-309. https://doi.org/10.1378/chest.06-2711.

154. Troianos CA, Hartman GS, Glas KE, et al. Special articles: guidelines for performing ultrasound guided vascular cannulation: recommendations of the American Society of Echocardiography and the Society of Cardiovascular Anesthesiologists. Anesth Analg. 2012;114(1):46-72. https://doi. org/10.1213/ANE.0b013e3182407cd8

155. Issenberg SB, McGaghie WC, Hart IR, et al. Simulation technology for health care professional skills training and assessment. JAMA. 1999;282(9):861-866. https://doi.org/10.1001/jama.282.9.861.

156. Millington SJ, Wong RY, Kassen BO, Roberts JM, Ma IW. Improving internal medicine residents' performance, knowledge, and confidence in central venous catheterization using simulators. J Hosp Med. 2009;4(7):410-416. https://doi.org/10.1002/jhm.570.

157. Beaulieu Y, Laprise R, Drolet $P$, et al. Bedside ultrasound training using webbased e-learning and simulation early in the curriculum of residents. Crit Ultrasound J. 2015;7:1. https://doi.org/10.1186/s13089-014-0018-9.

158. Barsuk JH, Cohen ER, McGaghie WC, Wayne DB. Long-term retention of central venous catheter insertion skills after simulation-based mastery learning. Acad Med. 2010;85(10 Suppl):S9-S12. https://doi.org/10.1097/ ACM.0b013e3181ed436c.

159. Wayne DB, Didwania A, Feinglass J, et al. Simulation-based education improves quality of care during cardiac arrest team responses at an academic teaching hospital: a case-control study. Chest. 2008;133(1):56-61. https://doi. org/10.1378/chest.07-0131.

160. Evans LV, Dodge KL, Shah TD, et al. Simulation training in central venous catheter insertion: improved performance in clinical practice. Acad Med. 2010;85(9):1462-1469. https://doi.org/10.1097/ACM.0b013e3181eac9a3.

161. Smith CC, Huang GC, Newman LR, et al. Simulation training and its effect on long-term resident performance in central venous catheterization. Simul Healthc J Soc Simul Healthc. 2010;5(3):146-151. https://doi.org/10.1097/ SIH.0b013e3181dd9672.

162. Laack TA, Dong Y, Goyal DG, et al. Short-term and long-term impact of the central line workshop on resident clinical performance during simulated central line placement. Simul Healthc J Soc Simul Healthc. 2014;9(4):228233. https://doi.org/10.1097/SIH.0000000000000015.

163. Dodge KL, Lynch CA, Moore CL, Biroscak BJ, Evans LV. Use of ultrasound guidance improves central venous catheter insertion success rates among junior residents. J Ultrasound Med. 2012;31(10):1519-1526. https://doi. org/10.7863/jum.2012.31.10.1519

164. Bayci AW, Mangla J, Jenkins CS, Ivascu FA, Robbins JM. Novel educational module for subclavian central venous catheter insertion using real-time ultrasound guidance. J Surg Educ. 2015;72(6):1217-1223. https://doi. org/10.1016/j.jsurg.2015.07.010.

165. Andreatta P, Chen Y, Marsh M, Cho K. Simulation-based training improves applied clinical placement of ultrasound-guided PICCs. Support Care Cancer Off J Multinat Assoc Support Care Cancer. 2011;19(4):539-543. https:// doi.org/10.1007/s00520-010-0849-2.

166. Rosen BT, Uddin PQ, Harrington AR, Ault BW, Ault MJ. Does personalized vascular access training on a nonhuman tissue model allow for learning and retention of central line placement skills? Phase II of the procedural patient safety initiative (PPSI-II). J Hosp Med. 2009;4(7):423-429. https://doi. org/10.1002/jhm.571.

167. Ault MJ, Rosen BT, Ault B. The use of tissue models for vascular access training. Phase I of the procedural patient safety initiative. J Gen Intern Med. 2006;21(5):514-517. https://doi.org/10.1111/j.1525-1497.2006.00440.x.

168. Varga S, Smith J, Minneti M, et al. Central venous catheterization using a perfused human cadaveric model: application to surgical education. J Surg Educ. 2015;72(1):28-32. https://doi.org/10.1016/j.jsurg.2014.07.005.

169. Sansivero GE. Venous anatomy and physiology. Considerations for vascular access device placement and function. J Intraven Nurs Off Publ Intraven Nurs Soc. 1998;21(5 Suppl):S107-S114.

170. Eisen LA, Narasimhan M, Berger JS, et al. Mechanical complications of central venous catheters. Journal of intensive care medicine. 2006;21(1):40-46. https://doi.org/10.1177/0885066605280884

171. Chenkin J, Lee S, Huynh T, Bandiera G. Procedures can be learned on the Web: a randomized study of ultrasound-guided vascular access training. Acad Emerg Med. 2008;15(10):949-954. https://doi.org/10.1111/j.15532712.2008.00231.x

172. Abualenain J, Calabrese K, Tansek R, Ranniger C. 319 Comparing standard versus video-based teaching for ultrasound-guided internal jugular central venous catheter access for fourth-year medical students. Ann Emerg Med. 
2014;64(4):S113. https://doi.org/10.1016/.annemergmed.2014.07.347.

173. Pustavoitau A, Blaivas M, Brown SM, et al. Recommendations for achieving and maintaining competence and credentialing in critical care ultrasound with focused cardiac ultrasound and advanced critical care echocardiography. Crit Care Med. 2016.

174. Jensen TP, Soni NJ, Tierney DM, Lucas BP. Hospital privileging practices for bedside procedures: A survey of hospitalist experts. J Hosp Med. 2017;12(10):836-839. https://doi.org/10.12788/jhm.2837.

175. Moureau N, Lamperti M, Kelly LJ, et al. Evidence-based consensus on the insertion of central venous access devices: definition of minimal requirements for training. Br J Anaesth. 2013;110(3):347-356. https://doi.org/10.1093/bja/ aes499.

176. Ernst A, Silvestri GA, Johnstone D, American College of Chest Physicians. Interventional pulmonary procedures: guidelines from the American College of Chest Physicians. Chest. 2003;123(5):1693-1717. https://doi.org/10.1378/ chest.123.5.1693.

177. Thomas SM, Burch W, Kuehnle SE, et al. Simulation training for pediatric residents on central venous catheter placement: a pilot study. Pediatr Crit Care Med J Soc Crit Care Med.. 2013;14(9):e416-e423. https://doi.org/10.1097/ PCC.0b013e31829f5eda.

178. Smith KK, Gilcreast D, Pierce K. Evaluation of staff's retention of ACLS and BLS skills. Resuscitation. 2008;78(1):59-65. https://doi.org/10.1016/j.resuscitation.2008.02.007.

179. Ericsson KA. Deliberate practice and the acquisition and maintenance of expert performance in medicine and related domains. Acad Med. 2004;79(10 Suppl):S70-S81. https://doi.org/10.1097/00001888-200410001-00022.

180. Gerard JM, Thomas SM, Germino KW, et al. The effect of simulation training on PALS skills among family medicine residents. Fam Med. 2011;43(6): 392-399.

181. Brydges R, Nair P, Ma I, Shanks D, Hatala R. Directed self-regulated learning versus instructor-regulated learning in simulation training. Med Educ. 2012;46(7):648-656. https://doi.org/10.1111/j.1365-2923.2012.04268.x.

182. Wayne DB, Butter J, Siddall VJ, et al. Simulation-based training of interna medicine residents in advanced cardiac life support protocols: a random- ized trial. Teach Learn Med. 2005;17(3):210-216. https://doi.org/10.1207/ s15328015t/m1703_3.

183. Arthur Jr. W, Bennett Jr. W, Stanush PL, McNelly TL. Factors that influence skill decay and retention: A quantitative review and analysis. Hum Perform. 1998;11(1):57-101. https://doi.org/10.1207/s15327043hup1101_3.

184. Rusche JD, Besuner P, Partusch SK, Berning PA. Competency program development across a merged healthcare network. J Nurs Staff Dev. 2001;17(5):234-240; quiz 241-232. https://doi.org/10.1097/00124645200109000-00004.

185. O'Hearne Rebholz M. A review of methods to assess competency. J Nurs Staff Dev. 2006;22(5):241-245. https://doi.org/10.1097/00124645-20060900000007.

186. Reznick RK. Teaching and testing technical skills. Am J Surg. 1993;165(3):358361. https://doi.org/10.1016/s0002-9610(05)80843-8.

187. Reznick RK, MacRae H. Teaching surgical skills--changes in the wind. N Engl J Med. 2006;355(25):2664-2669. https://doi.org/10.1056/NEJMra054785.

188. Murin S, Stollenwerk NS. Simulation in procedural training: at the tipping point. Chest. 2010;137(5):1009-1011. https://doi.org/10.1378/chest.10-0199.

189. American College of Emergency Physicians. Emergency ultrasound guidelines. Ann Emerg Med. 2009;53(4):550-570. https://doi.org/10.1016/j. annemergmed.2008.12.013.

190. Guilbert MC, Elkouri S, Bracco D, et al. Arterial trauma during central venous catheter insertion: case series, review and proposed algorithm. J Vasc Surg. 2008;48(4):918-925; discussion 925. https://doi.org/10.1016/j.jvs2008.04.046.

191. Dong Y, Suri HS, Cook DA, et al. Simulation-based objective assessment discerns clinical proficiency in central line placement: a construct validation. Chest. 2010;137(5):1050-1056. https://doi.org/10.1378/chest.09-1451.

192. Adhikari S, Theodoro D, Raio C, et al. Central venous catheterization: are we using ultrasound guidance? J Ultrasound Med. 2015;34(11):2065-2070. https://doi.org/10.7863/ultra.15.01027.

193. Mourad M, Kohlwes J, Maselli J, MERN Group, Auerbach AD. Supervising the supervisors--procedural training and supervision in internal medicine residency. J Gen Intern Med. 2010;25(4):351-356. https://doi.org/10.1007/s11606-0091226-z. 